\title{
Integrating Pricing and Inventory Control: Is it Worth the Effort?
}

\author{
Lisa Gimpl-Heersink, Institute for Production Management, Vienna University of Economics and Business Administration, \\ Email: lisa.gimpl-heersink@wu-wien.ac.at \\ Christian Rudloff, Institute for Production Management, Vienna University of Economics and Business Administration, \\ Email: crudloff@wu-wien.ac.at \\ Moritz Fleischmann, Rotterdam School of Management, Erasmus University, Email: MFleischmann@rsm.nl \\ Alfred Taudes, Institute for Production Management, Vienna University of Economics and Business Administration, \\ Email: Alfred.Taudes@wu-wien.ac.at*
}

\begin{abstract}
In this paper we first show that the gains achievable by integrating pricing and inventory control are usually small for classical demand functions. We then introduce reference price models and demonstrate that for this class of demand functions the benefits of integration with inventory control are substantially increased due to the price dynamics. We also provide some analytical results for this more complex model. We thus conclude that integrated pricing/inventory models could repeat the success of revenue management in practice if reference price effects are included in the demand model and the properties of this new model are better understood.
\end{abstract}

Keywords: Inventory Management, Pricing, Reference Price, Stochastic Demand Model

\section{Introduction}

\subsection{Problem Statement}

In the basic price-optimization problem, the only internal factor affecting the price of a monopolist is incremental cost, i.e. profit-optimal price $p^{*}$ is given by $p^{*}=c \eta\left(p^{*}\right) /\left(\eta\left(p^{*}\right)-1\right)$, where $\eta\left(p^{*}\right)$ is the price elasticity and $c \geq 0$, incremental cost (see, e.g., Phillips (2005), Chapter 1). In the case of linear demand $D(p)=\beta_{0}+\beta_{1} p$ with $\beta_{0}>0, \beta_{1}<0$, optimizing $(p-c) D(p)$ yields $p^{*}=\left(\beta_{1} c-\beta_{0}\right) / 2 \beta_{1}$ as the optimal price. This result is valid if enough inventory (capacity) is in place to satisfy the resulting demand $D\left(p^{*}\right)$ or if demand is deterministic and $D\left(p^{*}\right)$ is produced/procured after the pricing decision before the selling process starts. Inventory/capacity enters the pricing problem if the available inventory is smaller than $D\left(p^{*}\right)$ : in this case the optimal price is the run out price $p^{r}, D\left(p^{r}\right)=x$, where $x$ is the available inventory (capacity). Profit can be improved if different prices are charged to different market segments. This is done by either adjusting price over time

\footnotetext{
* This research was supported by the Vienna Science and Technology Fund (WWTF) under grant "Integrated Demand and Supply Chain Management" (Call "Mathematics and ...").
}

(so-called price-based revenue management) or by dynamically closing booking classes (so-called quantity-based revenue management) depending on the inventory/capacity remaining for the rest of the selling period (see e.g. Talluri and van Ryzin (2004)). This kind of integrated pricing and inventory (capacity) management has a profound impact on profitability and revenue management is accepted industry practice in the service sector (yield management for airlines, hotel, logistics service providers etc.) and retailing (markdown management of high-tech/fashion goods or sell-off items). In this paper we investigate the situation where inventory is adjustable, i.e. the inventory decision is made after or jointly with the pricing decision before demand materializes. Demand is uncertain, i.e. $D(p, \varepsilon)=\beta_{0}+\beta_{1} p+\varepsilon$, where $\varepsilon$ follows a distribution function $F(\cdot)$ with mean 0 and variance $\sigma^{2}$. This is typically the case in manufacturing or in retailing of goods with long life cycles and short procurement/production lead times ${ }^{1}$.

In many firms, pricing and inventory control is done sequentially in such situations. At first, mar-

\footnotetext{
1 We will thus only use the term inventory in the following, although the findings also hold for suitable settings in service industries, where the analogous concept is capacity.
} 
keting/sales autonomously determines a price that maximizes expected profit based on incremental costs $c$ only. This is then passed on to logistics (procurement or production) together with information on the demand distribution. Logistics then adds a safety stock to expected demand $E\left[D\left(p^{*}, \varepsilon\right)\right]$ to account for risk depending on shortage, holding and backlogging cost and salvage value. However, while computationally simple and well adapted to the usual division of labor in firms, in general the resulting prices and inventory policies are not optimal. As it was already shown in Whitin (1955), the optimal price resulting from a joint optimization of a price-setting Newsvendor Problem with lost sales differs from $p^{*}$. It seems natural to accelerate demand through a price discount in the case of overstocking in a multi-period setting. However, these gains have the prize of added complexity and intra-organizational coordination cost and practice will only adopt more elaborate models and business processes if the expected benefits outweigh this overhead. Classical works on integrated pricing and inventory control indicate profit increases through integration of only up to $2 \%$ for typical cases, which might be an explanation of why contrary to revenue management - such models are not widely implemented in IT-based planning systems so far.

\subsection{Existing Literature and Contribution of the Paper}

Yano and Gilbert (2004) and Elmaghraby and Keskinocak (2003) survey the literature on combined pricing/inventory control. Regarding the demand model, two streams of literature can be distinguished: the works in the operations management/logistics area assume classical demand models, where demand is influenced by the current price only. Here, the focus is on details of the logistic part. Inferences about the gains of integration are either done analytically (see, e.g., Petruzzi and Dada (1999)) or via numerical simulation (see, e.g., Federgruen and Heching (1999)). As stated above, these results show limited benefits.

Reference price models have been popular in marketing (see e.g. Mazumdar, Raj and Sinha (2005) for a survey). Here also the pricing history influences demand, as it is the basis of the expectation of future prices and acts as a benchmark to judge current prices: customers respond favorably if the current price is less than the reference price and unfavorably if the current price is higher than the reference price. To the best of our knowledge, the integration of reference price models with inventory control models has not been studied so far. We will probe into the issue of whether using a reference price model to describe demand increases the benefits of integration with a logistic model. Here, we study whether the base-stock list-price policy still holds in such a setting and infer the size of potential benefits via numerical simulation. In the survey part at the beginning of the paper we also complement existing literature by studying single-period joint pricing/inventory control with backlogging and by extending the steady-state reference price proof from Popescu and Wu (2007) to the case of positive ordering cost.

\subsection{Outline of the Paper}

In Section 2, we will briefly describe the sequential method in a single- and multi-period setting as the basis for a review of the integrated pricing and inventory decision models developed in literature and study the benefits of an integration in Section 3. In Section 4 we then extend the classical demand model by including reference price effects. In Section 5 we summarize our findings and identify areas for further research.

Generally, our focus is on linear demand models and monopolistic pricing. While ensuring mathematical tractability these assumptions are not unrealistic: price optimization by a firm is only possible in imperfect markets and in the case of monopolistic competition a firm faces a range of prices where competitors do not react, i.e. the linear demand function is a local approximation conditional on competitors' prices which remain unchanged if the price stays within this permissible range (see Phillips (2005), Chapter 1). For the logistic part we only look at the determination of the inventory/production level. Consistent with the inventory literature we will therefore denote $c$ as ordering cost. We also focus on the backlogging case,$^{2}$ where unsatisfied demand is fully satisfied in later periods and backlogging costs are charged and assume no fixed ordering costs.

\footnotetext{
2 A line of related research concentrates on partial backlogging either for non-perishable goods (see e.g. Abad (2001)) or perishable goods (see e.g. Dye, Hsieh and Ouyang (2007)).
} 


\section{Sequential Models}

\subsection{Newsvendor Models}

In the case of a perishable product that becomes obsolete at the end of a single period and where unsatisfied demand is lost, in the sequential model logistics solves the well-known classical Newsvendor Problem (see, e.g., Petruzzi and Dada (1999)). In the first step marketing/sales determines the profit-optimal price as

$$
p^{*}=-\frac{\beta_{0}-\beta_{1} c}{2 \beta_{1}}
$$

due to the fact that $E[\varepsilon]=0$. Then, $p^{*}$ and information on demand risk is passed on to logistics, which determines the optimal inventory level $y^{*}$ as

$$
\text { (2) } y^{*}=E\left[D\left(p^{*}, \varepsilon\right)\right]+F^{-1}\left(\frac{p^{*}+s-c}{p^{*}+s-v}\right) \text {, }
$$

where $s \geq 0$, denotes the shortage cost and $v$ the salvage value (or salvage cost if $v<0$, respectively). Here $C_{u}=\left(p^{*}+s-c\right)$ represents the opportunity cost of underestimating demand and $C_{o}=(c-v)$ the cost of overestimating demand. The above ratio $C_{u} /\left(C_{u}+C_{o}\right)$ in equation (2) is known as the critical fractile. Intuitively, it corresponds to the safety factor at which the expected profit lost from being one unit short is equal to that from being one unit over.

Logistics employs a different model if demand in excess of the amount stocked is backlogged. In this case, customers will return after the end of the period where there is one more chance to place an order for the outstanding items, which are then instantaneously delivered to the customers ${ }^{3}$. But, at the same time, backlogging costs $b \geq 0$, are charged as penalty costs for the inability to meet consumer needs when they occur. In cases of overproduction with resultant excess of inventories at the end of the period, holding costs $h \geq 0$ occur. These could be interpreted as carrying charges until the remaining items can be sold e.g. to a discount store for some salvage value $v$. Holding and backlogging costs are charged for the period when they occur, whereas any financial flow after the end of the period (reordering/salvaging opportunity) is discounted by a discount factor $0<\gamma \leq 1$. To insure that it is not optimal to not order anything at

\footnotetext{
3 Problems like these can be found as newsvendor models with an emergency supply option (see e.g. Montgomery, Ajit and Keswani (1973) and Khouja (1996)).
}

all and merely accumulate backlog penalty costs, also $b>(1-\gamma) c$ is assumed. Maximizing expected profits yields the optimal order quantity

$$
\text { (3) } y^{*}=E\left[D\left(p^{*}, \varepsilon\right)\right]+F^{-1}\left(\frac{b-(1-\gamma) c}{h+b-\gamma(v-c)}\right) \text {. }
$$

To see this we differentiate the expected one-period profit

$$
\text { (4) } \begin{aligned}
& E\left[P\left(y, p^{*}\right)\right]=p^{*} E\left[D\left(p^{*}, \varepsilon\right)\right]-c y \\
& -(h-\gamma v) \int_{-\infty}^{y-E\left[D\left(p^{*}, \varepsilon\right)\right]}\left(y-E\left[D\left(p^{*}, \varepsilon\right)\right]-u\right) f(u) d u \\
& -(b+\gamma c) \int_{y-E\left[D\left(p^{*}, \varepsilon\right)\right]}^{\infty}\left(E\left[D\left(p^{*}, \varepsilon\right)\right]+u-y\right) f(u) d u
\end{aligned}
$$

with respect to the inventory $y$. This leads to

(5)

$$
\begin{aligned}
& \frac{\partial E\left[P\left(y, p^{*}\right)\right]}{\partial y} \\
= & -c-(h-\gamma v) F\left(y-E\left[D\left(p^{*}, \varepsilon\right)\right]\right) \\
& -(b+\gamma c) F\left(y-E\left[D\left(p^{*}, \varepsilon\right)\right]\right)+(b-\gamma c) .
\end{aligned}
$$

Setting this equal to zero and solving for $y$ gives the desired result.

The critical fractile $(b-(1-\gamma) c) /(h+b-\gamma(v-c))$ has a similar interpretation as in equation 2: it corresponds to the order quantity at which the expected profit lost from being one unit short is equal to that from being one unit over. Here $C_{u}=(b-(1-\gamma) c)$ denotes the opportunity cost of underestimating demand and $C_{o}=(h+c-$ $\gamma v$ ) the cost of overestimating demand. The above ratio is again given by $C_{u} /\left(C_{u}+C_{o}\right)$. Note that in the backlogging case $p^{*}$ does not appear in the critical fractile. This is because the items are sold in any case. Today, the situation characterized by formula (3) is more prevalent in practice, as due to competition, firms are willing to incur substantial backlogging cost rather than lose customers in the future due to unsatisfied demand.

\subsection{Multi-Period Models}

We now turn to the dynamic version of the backlogging inventory model which was first introduced and solved by Arrow, Harris and Marschak (1951). Here the system described will be operated over $T$ periods. What makes the problem more complicated than solving $T$ copies of the single-period problem is that any leftover stock at the end of 
Figure 1: Inventory Path

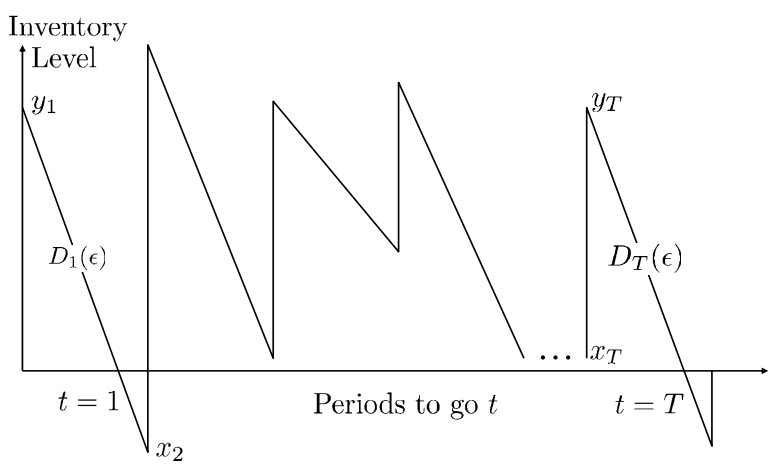

one period is retained and can be offered for sale the following period (see Figure 1 for a sample inventory path). In this regard, each unit of positive leftover stock at the end of each period incurs holding costs $h$. Demand for the product in excess of the amount stocked will be backlogged, which means that these customers will return the next period for the product, in addition to the usual random number of customers. A per-unit backlogging cost $b$ is charged as a penalty cost for each unit that is backlogged in each period. The newly arising demands in different periods are assumed to be statistically independent. As in the above section a proportional per-unit ordering cost of $c$ is incurred, and orders placed are essentially received immediately (received in time to meet demand that arises in that period). All costs are expressed in beginning-of-period cash units, cash flows occurring in subsequent time periods are discounted by a one-period discount factor $\gamma \in(0,1]$. After the last period, the remaining inventory is salvaged or backlogged demand is satisfied.

A convenient way to represent the state of a system in this model is the level $x$ of inventory before ordering. Positive $x$ indicates leftover stock at the end of the period, negative $x$ unmet demand of the previous period (see Figure 1). The objective is to find an optimal order-up-to level $y_{t}$ for each period $t$ in order to maximize total expected discounted profits:

$$
\begin{gathered}
\sum_{t=1}^{T} \gamma^{t-1} \max _{y_{t}}\left(p_{t}^{*} E\left[D\left(p_{t}^{*}, \varepsilon_{t}\right)\right]-c\left(y_{t}-x_{t}\right)\right. \\
\left.-G\left(y_{t}, p_{t}^{*}\right)\right)+\gamma^{T} L\left(y_{T}, p_{T}^{*}\right),
\end{gathered}
$$

with $D\left(p_{t}^{*}, \varepsilon_{t}\right)=\beta_{0}+\beta_{1} p_{t}^{*}+\varepsilon_{t}$, where $\beta_{0}$ also includes the effect of demand drivers other than price (e.g. trend, seasonality, promotions, etc.),
Figure 2: Optimal inventory level after ordering

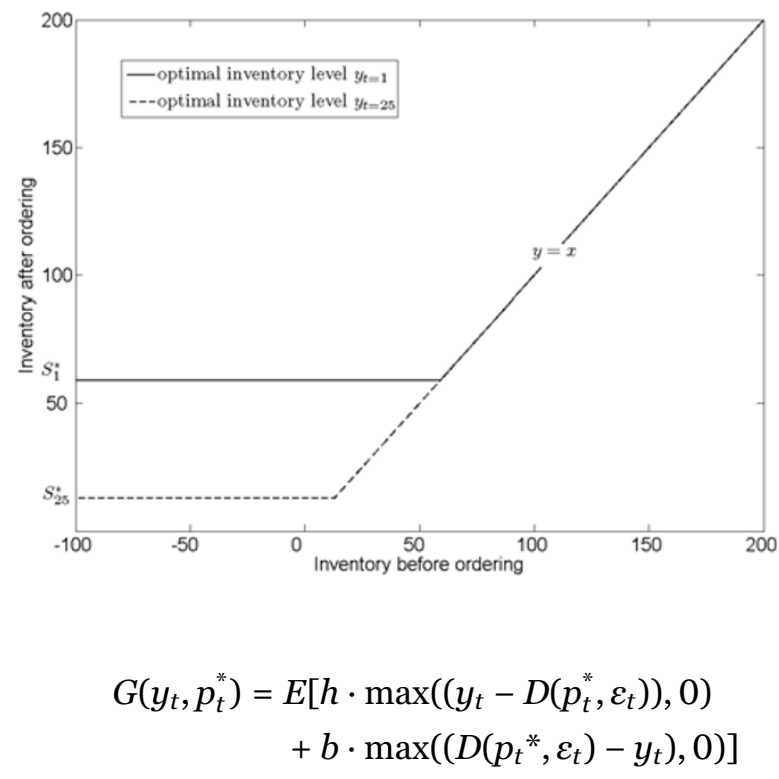

are the expected inventory holding/backlogging costs and $L\left(y_{T}, p_{T}^{*}\right)=E\left[v \cdot \max \left(\left(y_{T}-D\left(p_{T}^{*}, \varepsilon_{T}\right)\right), 0\right)+\right.$ $\left.c \cdot \max \left(\left(D\left(p_{T}^{*}, \varepsilon_{T}\right)-y_{T}\right), 0\right)\right]$ the expected salvage value (costs)/ backlogging costs in the last pe$\operatorname{riod} T$. Note that we are only using the timeinvariant demand and inventory costs. Many results are also possible in the time variant case but are omitted for clarity of the formulas.

This problem is mostly stated in literature in terms of dynamic programming:

$$
\begin{aligned}
V_{t}\left(x_{t}\right) & =\max _{y}\left\{p_{t}^{*} E\left[D\left(p_{t}^{*}, \varepsilon_{t}\right)\right]-c\left(y-x_{t}\right)\right. \\
& \left.-G\left(y, p_{t}^{*}\right)+\gamma E\left[V_{t+1}\left(y-D\left(p_{t}^{*}, \varepsilon_{t}\right)\right)\right]\right\},
\end{aligned}
$$

with $V_{T+1}=L\left(y_{T}, p_{T}^{*}\right)$.

Bellman, Glicksberg and Gross (1955) were the first to show that the optimal cost function is convex in inventory before ordering $x_{t}$, which leads to the result that a stock level independent of the inventory level before ordering is optimal. This level is often referred to as the base-stock level. If the initial inventory level $x_{t}$ is below the base-stock level, an order is placed to raise the inventory level $y_{t}$ to the base-stock level $S_{t}$, otherwise, no order is placed (see Figure 2). 4

Figure 3 shows that for the finite horizon case with no salvage value, the optimal base-stock level is

4 E.g. Zheng (1991) extends this result to a case of additional fixed ordering costs. Using the property of k-convexity they show that an $(s, S)$-policy is optimal, where the order-up-to level is again given by a constant, but an order is only placed if the inventory level before ordering is below another constant level. 
Figure 3: Base-stock path over time

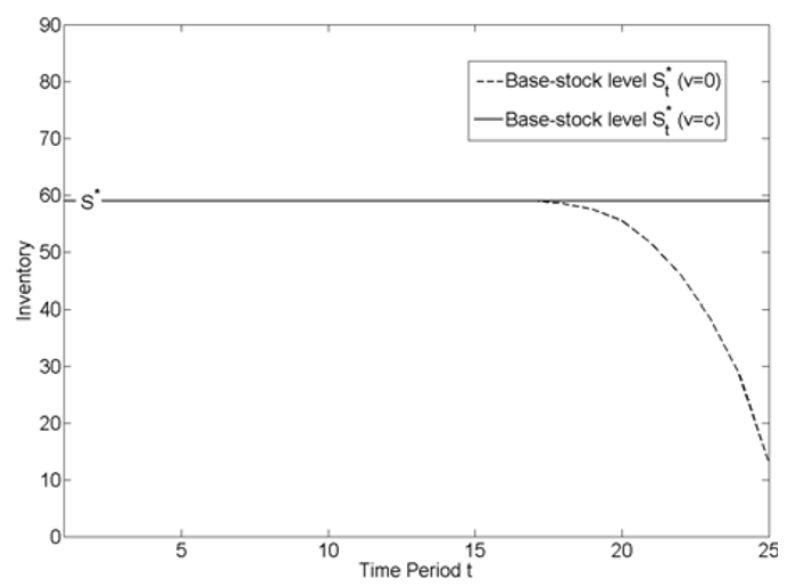

decreasing over time. That is because towards the end of the planning horizon, since time remaining is getting shorter, the risk of not selling the inventory on stock is increasing, against which costs the decision maker hedges by a diminishing basestock level. Of course no risk is observed in the case where the per unit salvage value equals the per unit ordering costs $(v=c)$. In this case, if some inventory on stock is not sold by the end of the horizon, it can be salvaged by the same amount of money as it was ordered. Here, a myopic policy which looks only at the single-period backlogging problem described in Subsection 2.1 is optimal in every period, regardless of the time horizon $T$. In other words a steady-state solution for the infinite horizon case can be simulated by setting $v=c$. The steady-state base-stock is given by

$$
y^{*}=E\left[D\left(p^{*}, \varepsilon\right)\right]+F^{-1}\left(\frac{b-(1-\gamma) c}{h+b}\right) .
$$

This can be shown analytically by rearranging terms and extending equation (6) to the infinite horizon case in the following way. We replace $x_{t+1}=y_{t}-D\left(p_{t}\right)$ for all $t \geq 1$ and then rearrange the sum in such a way that we are left only with terms indexed by $t+1$ in the $t$-th summand:

$$
\text { (9) } \begin{aligned}
V\left(x_{1}\right)=\sum_{t=0}^{\infty} \gamma^{t} \max _{y_{t+1}}\left[p^{*} E\left[D\left(p^{*}, \varepsilon_{t+1}\right)\right]\right. \\
-c\left(\left(y_{t+1}+x_{t+1}\right)-G\left(y_{t+1}, p^{*}\right)\right] \\
=c x_{1}+\sum_{t=0}^{\infty} \gamma^{t} \max _{y_{t+1}}\left[p^{*} E\left[D\left(p^{*}, \varepsilon_{t+1}\right)\right]\right. \\
\left.-c\left((1-\gamma) y_{t+1}+\gamma D\left(p^{*}\right)\right)-G\left(y_{t+1}, p^{*}\right)\right] .
\end{aligned}
$$

As we assume that we are in a steady state we replace the time-dependent $y_{t}$ by in time-invariant $y$. Since the profit function $V\left(x_{1}\right)$ is a concave function in $y$, the optimal inventory level after ordering $y^{*}$ can now be obtained by differentiating $V\left(x_{1}\right)$ with respect to $y$ and setting the result equal to zero. Using Leibniz integration rule we can differentiate the expected inventory costs to get $\frac{\partial}{\partial y} G\left(y, p^{*}\right)=-b+(h+b) F\left(y-E D\left(p^{*}\right)\right)$ where $F(\cdot)$ is the cumulative distribution function of the demand's random perturbation $\varepsilon$. Hence, to find the steady-state solution $y^{*}$, we solve

$$
\begin{aligned}
\frac{\partial}{\partial y} V\left(x_{1}\right)= & \frac{1}{1-\gamma}(-(1-\gamma) c+b \\
& \left.-(h+b) F\left(y-E D\left(p^{*}\right)\right)\right) \\
= & 0,
\end{aligned}
$$

which results in equation (8).

Table 1 displays the optimal steady-state basestock level $S^{*}$, which is the optimal order-up-to level, if the inventory before ordering is smaller then $S^{*}$. We investigate the effect on the optimal solution for various parameter settings. The base parameters are: $\beta_{0}=100, \beta_{1}=-20, h=0.005$, $b=0.4, \sigma=40, \gamma=1, D(p, \varepsilon) \sim$ normal. According to Phillips (2005) we set the price to $p^{*}=2.75$. Since $F^{-1}(\cdot)$ is increasing in both discount factor $\gamma$ and backlogging costs $b$, the steady state base-stock level $S^{*}$ is also increasing in these parameters. An intuitive explanation for the changes in backlogging costs could be that the seller wants to hedge against higher backlogging costs by keeping higher inventory levels. Furthermore, a higher uncertainty in demand also results in higher safety stock levels and hence in higher base-stock levels. This is illustrated in Table 1 by varying one of the parameters in each row. Numerical results also show that for more heavy tailed distributed demands (like the beta or the log-normal distribution) base-stock levels are higher to prepare for the higher risk of large demands.

Table 1: Steady-state base-stock level $\boldsymbol{S}^{*}$

\begin{tabular}{lcccr}
$b$ & 0.05 & 0.09 & 0.16 & 0.4 \\
\hline$S_{b}^{*}$ & 40 & 64 & 81 & 103 \\
\hline$\sigma$ & 10 & 20 & 40 & 60 \\
\hline$S_{b}^{*}$ & 59 & 74 & 103 & 132 \\
\hline$\gamma$ & 0.75 & 0.85 & 0.95 & 1 \\
\hline$S_{b}^{*}$ & 64 & 79 & 103 & 135 \\
\hline
\end{tabular}




\section{Classical Joint Pricing and Inventory Control Models}

\subsection{The Price Setting Newsvendor Problem}

We now look at the Newsvendor Problem when price and inventory level are jointly optimized. We will start with the lost sales case, which is studied in Whitin (1955), Thomas (1974) and surveyed in Petruzzi and Dada (1999). If we define the safety stock $z=y-E[D(p, \varepsilon)]$, the goal function is

$$
\begin{aligned}
& E[P(z, p)]= \\
& \int_{-\infty}^{z}(p(E[D(p, \varepsilon)]+u)+v(z-u)) f(u) d u \\
& -\int_{z}^{\infty}(p(E[D(p, \varepsilon)]+z)-s(u-z)) f(u) d u \\
& -c(E[D(p, \varepsilon)]+z)
\end{aligned}
$$

As Petruzzi and Dada (1999) show, $E[P(z, p)]$ is concave in $z$ for a given $p$ and concave in $p$ for a given $z$. One can thus reduce the optimization of (11) to an optimization problem in a single variable, first solving for the optimal value of $z$ as a function of $p$ and then substituting the result into $E[P(z, p)]$, which yields the fractile rule from equation (2), or by first optimizing $p$ for a given $z$ and then searching over the resulting optimal trajectory to maximize $E[P(z, p)]$. In this case the optimal price for the integrated problem is given as (see Petruzzi and Dada (1999))

$$
p_{1}^{*}=-\frac{\beta_{0}-\beta_{1} c}{2 \beta_{1}}+\frac{\Theta(z)}{2 \beta_{1}},
$$

where $\Theta(z)=\int_{z}^{\infty}(u-z) f(u) d u$ denotes the expected lost sales when safety stock $z$ is chosen. Thus, since $\beta_{1}<0$, the sequential method yields a price that is higher than the optimal price for the integrated problem and a gain can be achieved by more closely coordinating marketing and logistics. In the integrated setting the price is used to reduce the coefficient of variation of demand, and the difference between the optimal price set by marketing in isolation is decreasing with increased price sensitivity (slope of the demand function $\beta_{1}$ ) and demand uncertainty. However, as Petruzzi and Dada (1999) show, this effect is reversed if randomness is modelled in a multiplicative way as $D(p)=\left(\beta_{0}+\beta_{1} p\right) \cdot \varepsilon$.

Let us now look at the backlogging case. If we fix $z=y-E[D(p, \varepsilon)]$, the price does not influence holding/backlogging costs anymore. This differs from the lost sales case, where we lose sales if demand exceeds stock and hence revenue gets reduced by $p \cdot(\varepsilon-z)$. Differentiating the expected profit (4) with respect to price yields

(13) $\frac{\partial E[P(y, p)]}{\partial p}=E[D(p, \varepsilon)]+(p-c) E\left[D_{p}(p, \varepsilon)\right]$,

where $E\left[D_{p}(p, \varepsilon)\right]=\frac{\partial E[D(p, \varepsilon)]}{\partial p}$. Setting (13) equal to zero and solving for $p$ leads to $p^{*}$ as given in (1) being optimal, i.e. in the backlogging case, we can set the price independently of the inventory decision. Thus, while the sequential approach is not optimal in the lost-sales case, no gain is achieved by joint optimization in the backlogging case.

\subsection{Multi Period Joint Pricing and Inventory Control}

The multiple period joint pricing and inventory control problem has been studied e.g. by Federgruen and Heching (1999), Chen and Simchi-Levi (2004a) and Chen and Simchi-Levi (2004b). Here in each period the level of inventory before ordering $x$ is observed and on this basis both $y$ and $p$ are set, with the intuition that holding costs can be reduced by accelerating demand via reducing $p$.

Let $V_{t}\left(x_{t}\right)$ be the maximum expected profit from period $t$ onwards (profit-to-go function), with initial inventory $x_{t}$. Then the recursive Bellman equation has the following form:

(14) $V_{t}\left(x_{t}\right)=\max _{y_{t} \geq x_{t}, p_{t}}\left\{J_{t}\left(x_{t}, y_{t}, p_{t}\right)\right\}$

$$
\begin{aligned}
J_{t}\left(x_{t}, y_{t}, p_{t}\right)= & E\left[P_{t}\left(x_{t}, y_{t}, p_{t}, \varepsilon_{t}\right)\right] \\
& +\gamma E\left[V_{t+1}\left(y_{t}-D\left(p_{t}, \varepsilon_{t}\right)\right)\right]
\end{aligned}
$$

with $P_{t}\left(x_{t}, y_{t}, p_{t}, \varepsilon_{t}\right)=p_{t}\left(\beta_{0}+\beta_{1} p_{t}+\varepsilon_{t}\right)-c\left(y_{t}-x_{t}\right)-$ $G\left(y_{t}, p_{t}\right)$ and the boundary condition $V_{T}^{*}\left(x_{T}\right)=$ 0 for all $x_{T}$. Following Federgruen and Heching (1999), we reformulate (14) and (15) such that $V_{t}\left(x_{t}\right)$ is reduced by $c x_{t}$ with $G\left(y_{t}, p_{t}\right)$ being defined as in (6):

(16)

$$
\begin{aligned}
V_{t}\left(x_{t}\right)=\max _{y \geq x, p} J_{t}\left(y_{t}, p_{t}\right) \\
\begin{aligned}
J_{t}\left(y_{t}, p_{t}\right)= & \left(p_{t}-\gamma c\right) E\left[D\left(p_{t}\right)\right] \\
& -c(1-\gamma) y_{t}-G\left(y_{t}, p_{t}\right) \\
& +\gamma E\left[V_{t+1}^{*}\left(y_{t}-D\left(p_{t}, \varepsilon_{t}\right)\right]\right.
\end{aligned}
\end{aligned}
$$

and $V_{T}\left(x_{T}\right)=c x_{T}$ for all $x_{T}$. 
For this model, Federgruen and Heching (1999) use joint concavity to show optimality of a basestock policy and submodularity 5 in $y$ and $p$ to show optimality of a list-price policy. That means that in time period $t$, if the current inventory level $x_{t}$ is below the base-stock, inventory is increased to $y_{t}$ and the price $p_{t}^{*}$ is charged. Otherwise, no order is placed and a discount that increases with $x_{t}$ is given. Here, $p_{t}^{*}$ is called list price, as it resembles the price level without discounting.

Similar to the steady state of model (6) one can find a steady state for the joint pricing and inventory control model (14) and (15). For the linear demand case the steady states are given as follows: the steady-state price is

$$
p^{*}=-\frac{\beta_{0}-\beta_{1} c}{2 \beta_{1}}
$$

while the steady-state base-stock is

(19) $y^{*}\left(p^{*}\right)=E\left[D\left(p^{*}, \varepsilon\right)\right]+F^{-1}\left(\frac{b-(1-\gamma) c}{h+b}\right)$.

Note that the optimal steady-state price $p^{*}$ equals the optimal price from Section 1.1. The proof works exactly like the proof in Section 2.2. Again we rearrange the infinite sum (compare formula (9)) and replace the time variant variables $y_{t}$ and $p_{t}$ by their time-invariant counterparts $y$ and $p$. In order to find the steady-state base-stock $y^{*}\left(p^{*}\right)$ (this time depending on the optimal steady state price $p^{*}$ of the joint pricing and inventory control model) we follow the steps from Section 2.2 to obtain the optimal steady-state base-stock (19). To find the steady-state price, we use $y^{*}(p)$ as an input for $y$ in the infinite sum representation of formula (15) and differentiate with respect to $p$. To find $p^{*}$ we have to make $y^{*}$ dependent on $p$ instead of $p^{*}$ and then optimize with respect to $p$ in order to obtain $p^{*}$. It is easy to see that in this case, $G\left(y^{*}(p), p\right)$ is a constant and does not depend on $p$ anymore. As $V\left(x_{1}\right)$ is concave in $p$, we need to solve

$$
\begin{aligned}
\frac{\partial}{\partial p} V\left(x_{1}\right) & =E[D(p, \varepsilon)]+\frac{\partial E[D(p, \varepsilon)]}{\partial p}(p-c) \\
& =0
\end{aligned}
$$

In the case of the linear demand function this yields equation (18). Note that the optimal steady-

5 For all $y_{1}>y_{2}, J\left(y_{1}, p\right)-J\left(y_{2}, p\right)$ is non-increasing in $p$.
Figure 4: Price trajectory for time period 5, 10 and 15

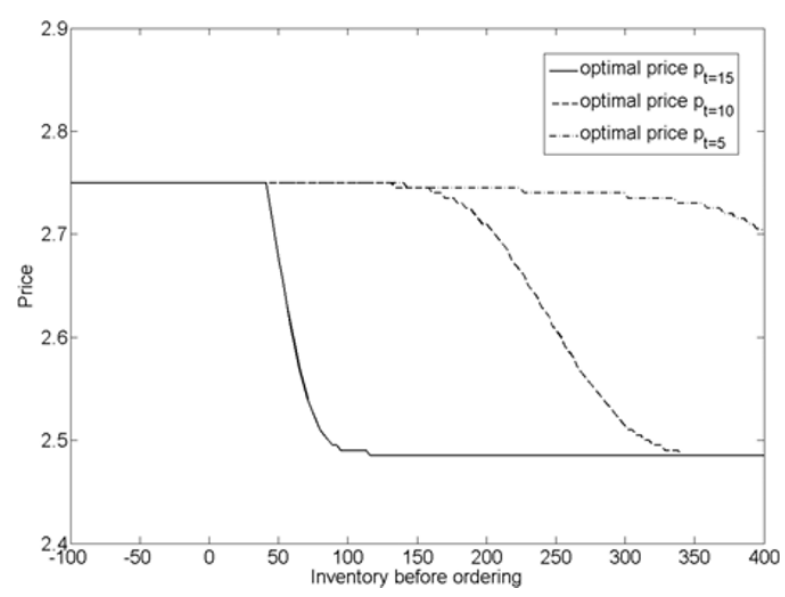

Figure 5: Base-stock and list-price evolution over time

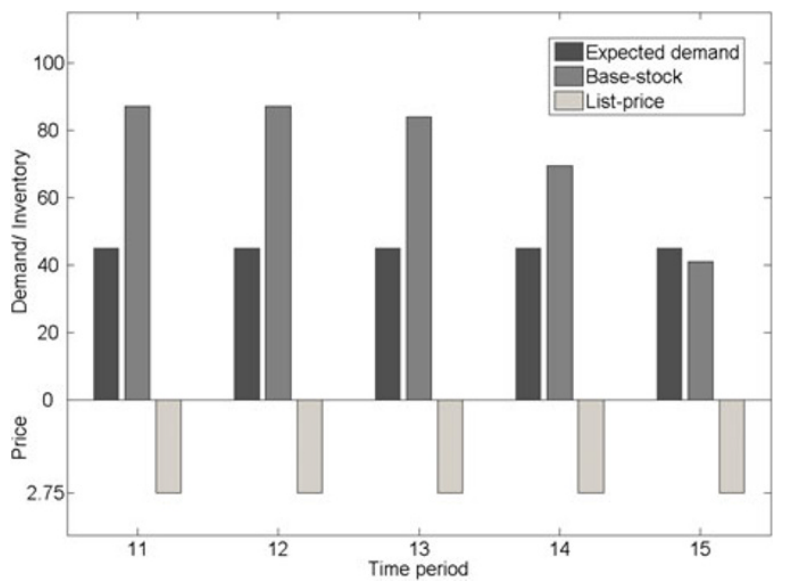

state price is the same as the optimal myopic price from Phillips (2005).

Figures 4 and 5 depict numerical results for (16) and (17) for a parameter setting similar to $\mathrm{Fe}$ dergruen and Heching (1999) with $\beta_{0}=100$, $\beta_{1}=-20, c=0.5, b=0.4, h=0.005, v=0$, $T=15$ and a coefficient of variation of 0.44 . Figure 4 shows the price as a function of the inventory before ordering for different periods. Figure 5 shows the base-stock, price and expected demand for the last periods of the planning horizon. One can see that while the base price stays constant over time, the tendency to give price discounts to lower inventory increases over time. Figure 6 depicts the gains of applying equations (16) and (17) versus the sequential procedure (1). We get the largest benefits of joint optimization towards the end of, or for a short planning horizon. In contrast to the comparisons in Federgruen and Heching (1999), 
Figure 6: Profit increase over time

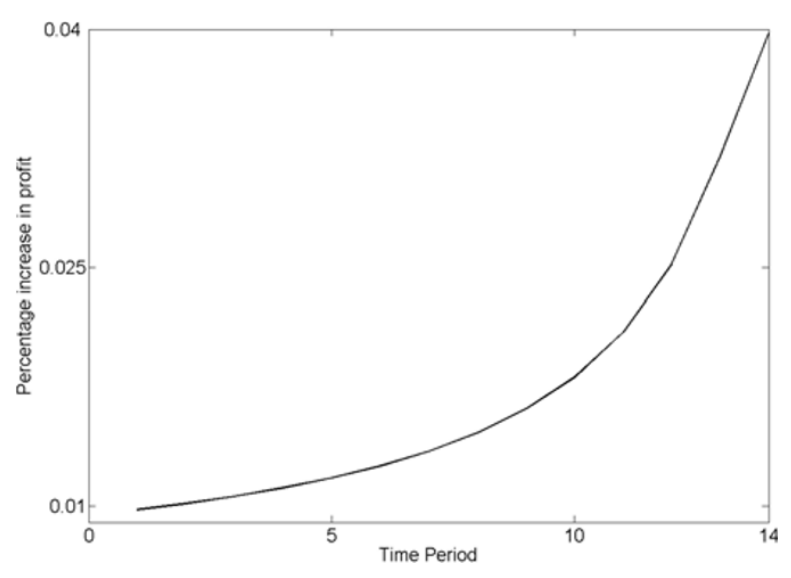

Figure 7: Profit increase in inventory level $x_{0}$

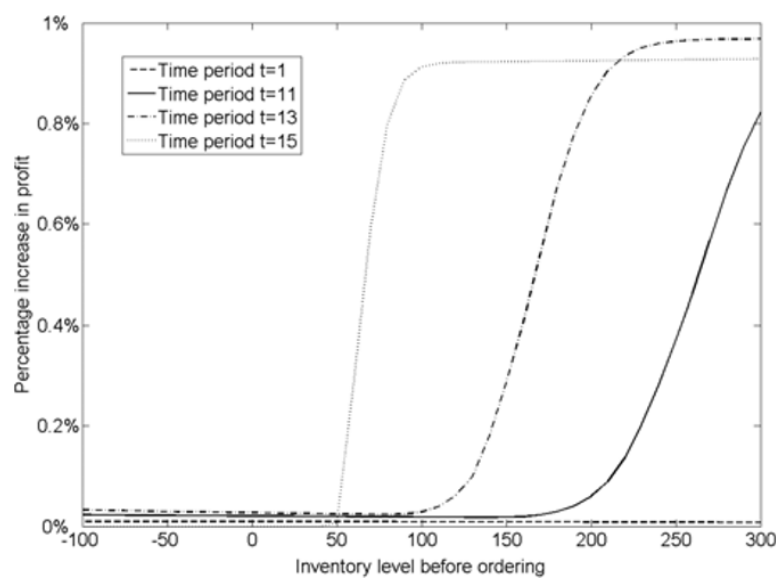

who base all numerical results on a coefficient of variation, we always use a constant standard deviation (not depending on price). This erodes a lot of the benefit when using a dynamic pricing model. Figure 7 shows relatively low benefits for low stock before ordering, which can be much higher for substantially larger inventory levels before ordering. The closer we get to the end of the planning horizon, the earlier this effect can be observed. This is intuitive as the seller tries to reduce the risk of being left with unsold stock at the end of the planning horizon.

\section{Joint Pricing and Inventory Control with Reference Price Effects}

\subsection{Reference Price Models}

Empirical studies like e.g. Winer (1986), Greenleaf (1995), Kopalle, Rao and Assuncao (1996), Bri- esch, Krishnamurthi, Mazumdar, and Raj (1997), Fibich, Gavious and Lowengart (2003), Mazumdar, Raj and Sinha (2005) and Natter, Reutterer, Mild, and Taudes (2006) show that for goods which are repeatedly bought from a monopolist, demand not only depends on the current price but is also sensitive to the firm's pricing history and thus accounts for intertemporal demand correlations. Since consumers have a memory, the carrier of price is not only based on its absolute level, but rather on its deviation from some reference level resulting from the pricing history. As customers revisit the firm, they develop price expectations, which become a benchmark against which current prices are compared. A formulation that captures this effect is the so-called reference price which is a standard price against which consumers evaluate the actual prices of products they are considering. If the price is below the reference price, the observed price is lower than anticipated, resulting in a perceived gain. This would make a purchase more attractive and raise demand. Similarly, the opposite situation would result in a perceived loss, reducing the probability of a purchase (people are less likely to buy products after prices have gone up). To include reference price effects, our linear demand model thus becomes (see e.g. Greenleaf (1995) or Kopalle, Rao and Assuncao (1996)):

$$
\begin{aligned}
D\left(p_{t}, r_{t}, \varepsilon_{t}\right)= & \beta_{0}+\beta_{1} \cdot p_{t} \\
& +\beta_{2} \cdot \max \left\{p_{t}-r_{t}, 0\right\} \\
& +\beta_{3} \cdot \min \left\{p_{t}-r_{t}, 0\right\}+\varepsilon_{t}
\end{aligned}
$$

with $\beta_{0} \geq 0, \beta_{1}, \beta_{2}, \beta_{3} \leq 0$ and $\varepsilon_{t}$ being iid. according to an arbitrary probability density function $f(\cdot)$ with mean $E\left[\varepsilon_{t}\right]=0$. Price and reference price $r_{t}$ are restricted to an arbitrary finite interval $[\underline{p}, \bar{p}]$ and $[r, \bar{r}]$ such that $E\left[D\left(p_{t}, r_{t}, \varepsilon_{t}\right)\right] \geq 0$.

If equation (21) is symmetric with respect to the effect of gains and losses $\left(\beta_{2}=\beta_{3}\right)$, buyers are loss-neutral and the demand function is smooth. For loss-averse consumers the demand function is steeper for losses than for gains $\left(\beta_{2}<\beta_{3}\right)$. In other words, a loss decreases expected demand more than an equivalently sized gain would increase demand (see Figure 8). This behavior is predicted by Prospect Theory (see e.g. Winer (1986)). If $\beta_{2}>\beta_{3}$, consumers are loss-seeking. As Slonim and Garbarino (2002) show, $\beta_{2}>\beta_{3}$ can also arise on the aggregate level when in fact the consumers behave according to Prospect Theory but stockpile when 
Figure 8: Prospect theory

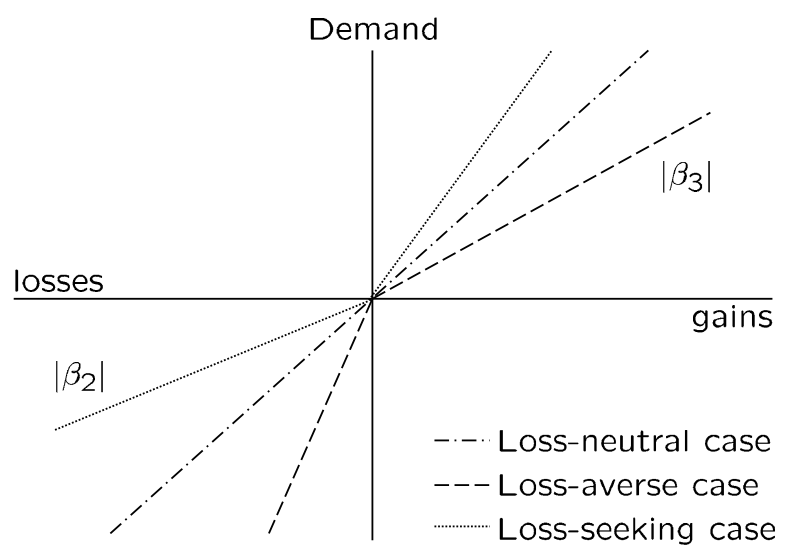

Figure 9: Formation of reference price

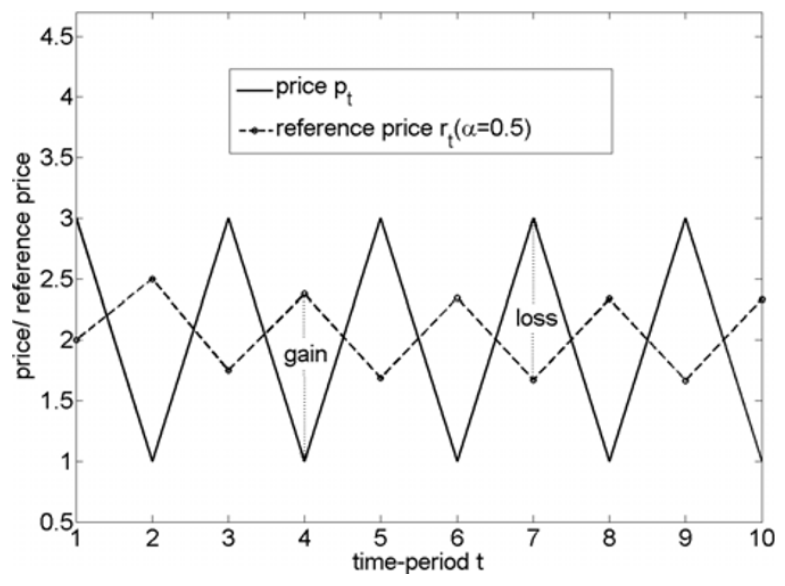

prices are low. We will focus on the loss-neutral and loss-averse case, which yield closed-formed steady-state solutions, while the optimal pricing policy in the loss-seeking case cycles (see Popescu and Wu (2007) and Figure 14).

A commonly used simple reference price updating mechanism is

(22) $r_{t}=\alpha r_{t-1}+(1-\alpha) p_{t-1}$,

where $0 \leq \alpha<1$ denotes the memory parameter and captures how strongly the reference price depends on past prices ${ }^{6}$ (see Figure 9). Lower values of $\alpha$ represent a shorter term memory; in particular if $\alpha=0$ the reference price equals the price of the previous period.

\footnotetext{
6 For a different, detailed exposition of reference price mechanisms, see e.g. Moon, Russell, and Duvvuri (2006).
}

In such a setting, the objective is to maximize total expected profits:

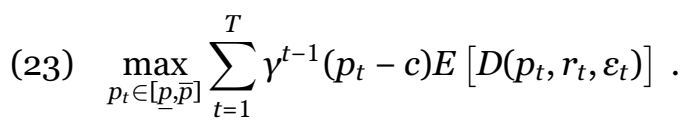

The decision which price to charge in each period is made in stages and cannot be viewed in isolation since one must balance the desire for high present profits, obtained by charging relatively low prices, against the undesirability of low future profits, resulting from the formation of a low reference price as a consequence of the earlier price discount. This tradeoff is captured by the technique of dynamic programming which at each stage ranks decisions based on the sum of the present values and the expected future values, assuming optimal decision making for subsequent stages. As the reference price summarizes past information which is relevant for future optimization, equation (23) is often written in terms of the Bellman equation:

$$
\begin{aligned}
V_{t}\left(r_{t}\right)= & \max _{p \in[\underline{p}, \bar{p}]}\left\{E\left[(p-c) D\left(p, r_{t}, \varepsilon_{t}\right)\right]\right. \\
& \left.+\gamma E\left[V_{t+1}\left(\alpha r_{t}+(1-\alpha) p\right)\right]\right\}
\end{aligned}
$$

An important consequence of this reference price formation is that although frequent price discounts may be beneficial in the short run, they may be dangerous in the long run when consumers get used to these discounts and reference prices drop. The reduced price becomes anticipated and loses its effectiveness, whereas the non-promoted price becomes unanticipated and would be perceived as a loss. Kopalle, Rao and Assuncao (1996) and Popescu and Wu (2007) show for time-constant parameters that if the reference level is initially high, an optimizing firm should consistently price below this level, which has the effect of a skimming strategy. Similarly a low initial reference level leads to the optimality of a penetration type strategy. According to Popescu and Wu (2007) the optimal price path converges (monotonously under certain assumptions) to a constant steady state which they only give for the case of zero ordering costs. Extending their results to the case $c>0$ leads to the following result for the the optimal steady-state price under the piecewise linear demand model of equation (21) for loss neutral $\left(\beta_{2}=\beta_{3}\right)$ or loss averse $\left(\beta_{2}<\beta_{3}\right)$ customer behavior: 
(25)

$$
p^{*}\left(r_{1}\right)= \begin{cases}p_{p}^{*}=\frac{\left(\beta_{1} c-\beta_{0}\right)(1-\alpha \gamma)+\beta_{2}(1-\gamma) c}{2 \beta_{1}(1-\alpha \gamma)+\beta_{2}(1-\gamma)} & \text { if } r_{1} \leq p_{p}^{*} \\ p_{s}^{*}=\frac{\left(\beta_{1} c-\beta_{0}\right)(1-\alpha \gamma)+\beta_{3}(1-\gamma) c}{2 \beta_{1}(1-\alpha \gamma)+\beta_{3}(1-\gamma)} & \text { if } r_{1} \geq p_{s}^{*} \\ r_{1} & \text { else. }\end{cases}
$$

Here, $p_{p}^{*}$ is the steady-state solution obtained by a penetration type strategy (if initial price expectations are low, start with a low price and monotonously increase it until the steady state is reached) and $p_{s}^{*}$ is the steady-state solution obtained by a skimming type strategy (if initial price expectations are high, start with a high price and monotonously decrease it until the steady state is reached).

Like in the steady-state proofs before, we again use differentiation of the infinite case of equation (23). We substitute $p_{t}=p$ and $r_{t+1}=\alpha^{t}\left(r_{1}-\right.$ $p)+p$ for all $t$, where $r_{1}$ is the starting reference price. In the linear demand case, this results in $V\left(r_{1}\right)=\sum_{t=0}^{\infty} \gamma^{t}\left[(p-c)\left(\beta_{0}+\beta_{1} p-\alpha^{t} \beta_{2}\left(r_{1}-p\right)\right)\right]$. Differentiating $V\left(r_{1}\right)$ with respect to $p$ and setting equal to 0 yields

$$
\begin{aligned}
& \frac{2 \beta_{1}}{1-\gamma} p+\frac{\beta_{2 / 3}}{1-\alpha \gamma}\left(2 p-r_{1}\right) \\
& +\frac{\beta_{0}-c \beta_{1}}{1-\gamma}-\frac{\beta_{2 / 3} c}{1-\alpha \gamma}=0 .
\end{aligned}
$$

Using the assumption that the reference price is in a steady state $r$ we set $r_{t}=r$ for all $t$. Hence, from equation (22) it follows that $r_{1}=p$. Since $V\left(r_{1}\right)$ is concave, solving this equation yields the steady-state price (25) for the loss neutral case. An extension for the proof to non-linear demand functions and the loss averse case can be found in Popescu and $\mathrm{Wu}$ (2007). Note, that if $\frac{\left(\beta_{1} c-\beta_{0}\right)(1-\alpha \gamma)+\beta_{2}(1-\gamma) c}{2 \beta_{1}(1-\alpha \gamma)+\beta_{2}(1-\gamma)}<r_{1}<\frac{\left(\beta_{1} c-\beta_{0}\right)(1-\alpha \gamma)+\beta_{3}(1-\gamma) c}{2 \beta_{1}(1-\alpha \gamma)+\beta_{3}(1-\gamma)}$, we have $p^{*}\left(r_{1}\right)=r_{1}$. As can be seen from equation (25), the steady-state price is the optimal price without reference price effects if $\alpha=0$ and $\gamma=0$ and $\beta_{2 / 3}=0$. Popescu and $\mathrm{Wu}$ (2007) also show that the steady-state price is decreasing in $\alpha$ and $\gamma$ and increasing in $\beta_{2 / 3}$. That is, it is the lower the smaller the reference price effect is. We use a base scenario of the demand model given in eq. (21) and set the parameters for loss neutral customer behavior to $\beta_{0}=100, \beta_{1}=-20, \beta_{2}=\beta_{3}=-40$ and $\beta_{2}=-50, \beta_{3}=-30$ for loss averse customers, respectively. Unless not stated differently we assume $\alpha=0.5, \gamma=0.5$. Table 2 shows how the
Table 2: Steady-state list price level $\boldsymbol{p}^{*}$

\begin{tabular}{llrl}
$\beta_{2}$ & -40 & \multicolumn{1}{l}{-20} & 0 \\
\hline$p_{\beta_{2}}^{*}$ & 4.3 & 4.38 & 4.5 \\
\hline$\gamma$ & 0 & 0.33 & 0.66 \\
\hline$p_{\gamma}^{*}$ & 4.25 & 4.28 & 4.33 \\
\hline$\alpha$ & 0.66 & 0.33 & 0 \\
\hline$p_{\alpha}^{*}$ & 4.29 & 4.31 & 4.33 \\
\hline
\end{tabular}

steady-state price $p^{*}\left(r_{1}\right)$ is influenced by successively varying the reference effect $\beta_{2}=\beta_{3}$, the discount rate $\gamma$ and the memory parameter $\alpha$.

Letting $\gamma=0$ equation (25) describes the oneperiod profit-optimizing price which we denote by $\widetilde{p}^{*}\left(r_{1}\right)$. By simple algebra and the fact that $\beta_{0}+\beta_{1} c \geq 0$ (since $p \geq c$ ) it is easy to see that $\widetilde{p}^{*}\left(r_{1}\right) \leq p^{*}\left(r_{1}\right)$, stating that the prices charged by a myopic firm are oblivious of their eroding effect on future demand, hence future profits. Denoting the optimal price in absence of a reference price by $\widehat{p}^{*}$ it is also easy to show that $p^{*}\left(r_{1}\right) \leq \widehat{p}^{*}$ for any $r_{1} \geq 0$. This means that in the long run, strategic firms should charge lower prices when consumers form reference effects, than when they do not. Bounds for the prices in Table 2 are $\widetilde{p}^{*}=4.25$ and $\widehat{p}^{*}=4.5$.

From equation (25) it also becomes clear that in the loss averse case there exists more than one steady state, depending on the initial reference price $r_{1}$. For initial price expectations lying between the two possible steady states $p_{p}^{*}$ and $p_{s}^{*}$, a constant pricing policy of the customer's initial price expectation $r_{1}$ is optimal (see Figure 10). Sample price paths for the loss neutral, loss averse and loss seeking case

Figure 10: Optimal price path (loss averse)

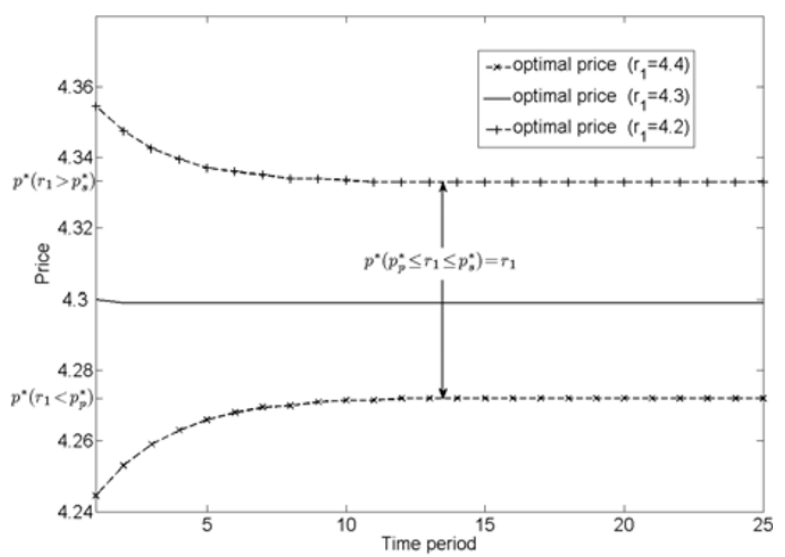


Figure 11: Optimal price and reference price path

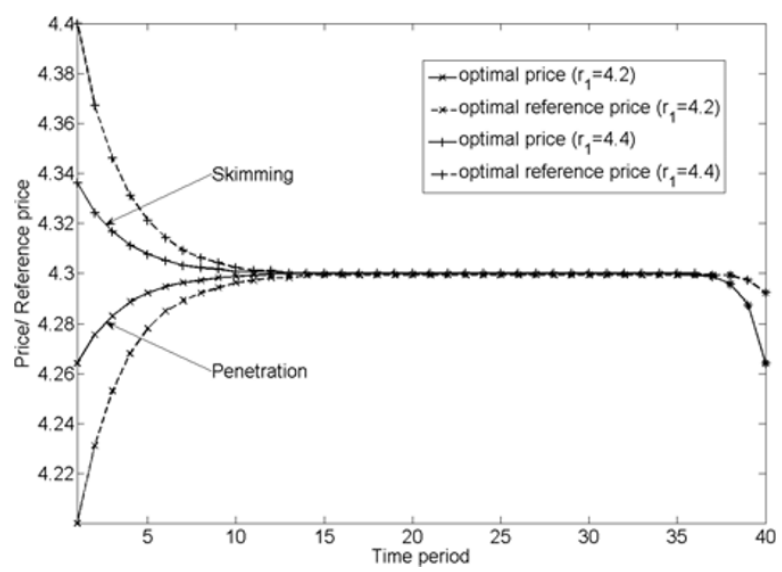

Figure 12: Optimal and myopic pricing policies

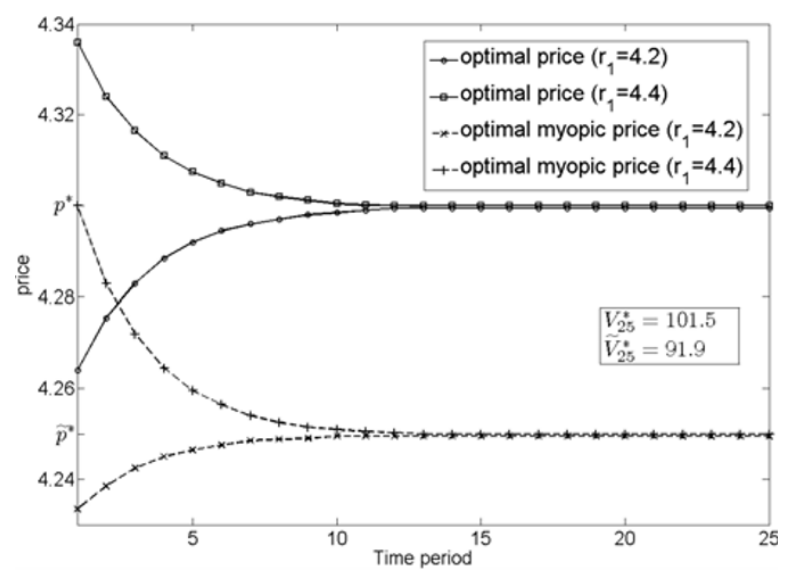

are given in figures 11 to 14 . Moreover, for those Figures we set $c=4$ and restrict price and reference price to the interval $p \in[4.2,4.4], r \in[4.2,4.4]$ ensuring nonnegative demand for any $p$ and $r$. Note that in the loss seeking case (see Figure 14) the optimal policy is cycling and not allowing for an analytical solution (see Popescu and Wu (2007)).

\subsection{Joint Pricing and Inventory Control under Reference Price Effects}

Not much is changed if reference effects are introduced in the one-period backlogging case: as the optimal inventory level is independent of the price, $r$ is only an additional parameter so that for the linear demand function the optimal price changes to

(27) $p_{1}^{*}(r)=\frac{-\beta_{0}+c \beta_{1}+\beta_{2 / 3}(r+c)}{2\left(\beta_{1}+\beta_{2 / 3}\right)}$,
Figure 13: Optimal steady-state price (loss averse)

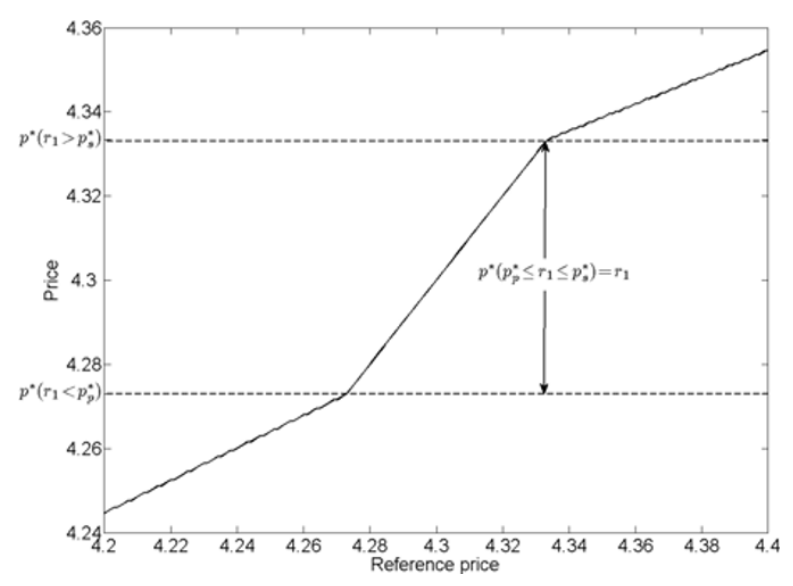

Figure 14: Optimal price path (loss seeking case)

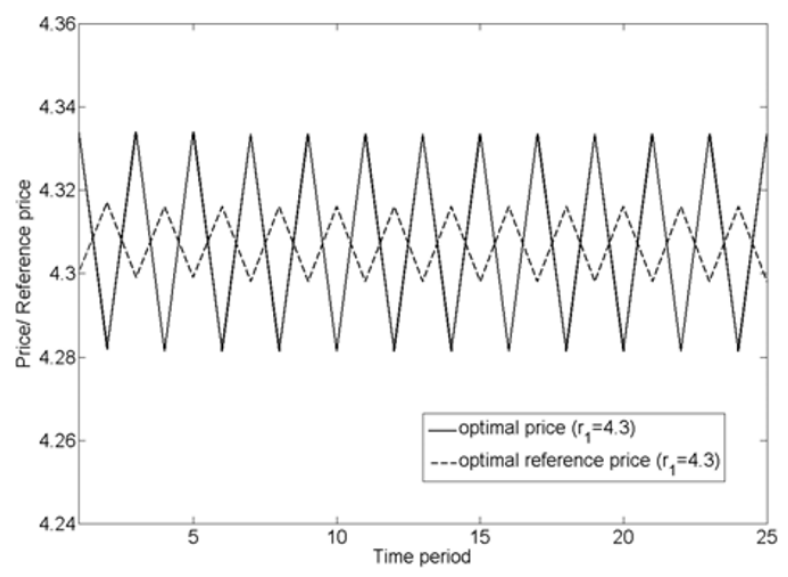

which is less than $p^{*}$ from the joint pricing and inventory control model without reference effects (see equation (18)) and increasing in the reference price $r$. The optimal order-up-to level $y^{*}$ is then given by (3) where $E\left[D\left(p^{*}, \varepsilon\right)\right]$ is replaced by the expected demand depending on the reference price as well. Not surprisingly, it can be seen that $p^{*}(r)$ is increasing in $r$, since a higher price can be charged when the customer is expecting it.

In the multi period case we now have a state space consisting of two variables, the initial inventory $x$ and the reference price $r$. Thus, the profit-to-go function is specified as $V_{t}^{*}\left(x_{t}, r_{t}\right)$ and the recursive Bellman equation has the following form:

$$
V_{t}^{*}\left(x_{t}, r_{t}\right)=\max _{y_{t} \geq x_{t}, p_{t}}\left\{J_{t}\left(x_{t}, y_{t}, p_{t}, r_{t}\right)\right\}
$$

$$
\begin{aligned}
& J_{t}\left(x_{t}, y_{t}, p_{t}, r_{t}\right)=E\left[P_{t}\left(x_{t}, y_{t}, p_{t}, r_{t}, \varepsilon_{t}\right)\right] \\
& \quad+\gamma E\left[V_{t+1}^{*}\left(y_{t}-D\left(p_{t}, r_{t}, \varepsilon_{t}\right), \alpha r_{t}+(1-\alpha) p_{t}\right)\right]
\end{aligned}
$$


with $P_{t}\left(x_{t}, y_{t}, p_{t}, r_{t}, \varepsilon_{t}\right)=p_{t}\left(\beta_{0}+\beta_{1} \cdot p_{t}+\beta_{2} \cdot \max \left\{p_{t}-\right.\right.$ $\left.\left.r_{t}, 0\right\}+\beta_{3} \cdot \min \left\{p_{t}-r_{t}, 0\right\}+\varepsilon_{t}\right)-c\left(y_{t}-x_{t}\right)-G\left(y_{t}, p_{t}, r_{t}\right)$ and the boundary condition $V_{T}^{*}\left(x_{T}, r_{T}\right)=0 \quad \forall x_{T}, r_{T}$. (Note that $G\left(y_{t}, p_{t}, r_{t}\right)$ is defined as in Section 2.2 with demand also depending on $r_{t}$.)

Reformulating equation (28) and (29) as in Federgruen and Heching (1999), such that $V_{t}^{*}\left(r_{t}, x_{t}\right)$ is reduced by $c x_{t}$, results in

$$
\begin{aligned}
& V_{t}^{*}\left(x_{t}, r_{t}\right)=\max _{y \geq x, p} J_{t}\left(y_{t}, p_{t}, r_{t}\right) \\
& J_{t}\left(y_{t}, p_{t}, r_{t}\right)=\left(p_{t}-\gamma c\right) E\left[D\left(p_{t}, r_{t}\right)\right] \\
& +-c(1-\gamma) y_{t}-G\left(y_{t}, p_{t}, r_{t}\right) \\
& +\gamma E\left[V_{t+1}^{*}\left(\alpha r_{t}+(1-\alpha) p_{t}, y_{t}-D\left(p_{t}, r_{t}, \varepsilon_{t}\right)\right]\right.
\end{aligned}
$$

and $V_{T}^{*}\left(r_{T}, x_{T}\right)=c x_{T}$ for all $r_{T}, x_{T}$.

In the general theory of stochastic dynamic programming it is well known that a model gains in complexity very quickly if the dimension of the state space increases. In this way, both finding the computational as well as the analytic solution of a model gets more complicated. However, if we assume joint concavity of the demand and revenue functions in all their variables, including the reference price $r$, an adaptation of the proof in Federgruen and Heching (1999) still works and one can show that a base-stock policy is optimal. The proof inductively shows that profit function $J_{t}(y, p, r)$ is jointly concave in $y, p$ and $r$ and thus the optimal profit $V_{t}^{*}(x, r)$ is jointly concave in $x$ and $r$ (for more details see Gimpl-Heersink, Rudloff, Fleischmann, and Taudes (2007)). While Federgruen and Heching (1999) can also show the optimality of a list-price policy, due to the additional complexity of the model in this section, a similar result has not been achieved so far. Unfortunately, the practical usefulness of this base-stock result is questionable as the joint concavity assumption in all three variables makes this proof unsuitable for many commonly used demand functions like the linear one. In this case joint concavity of the revenue function does not hold any longer.

However, since joint concavity in inventory level $y$ and price $p$ is sufficient for a base-stock policy, using the results of the one-period case, GimplHeersink, Rudloff, Fleischmann, and Taudes (2007) establish the optimality of a base-stock policy for the two-period model with linear demand. ${ }^{7}$ Changing the order of taking expected

\footnotetext{
7 A short sketch of the proof is given here. For a complete proof please see Gimpl-Heersink, Rudloff, Fleischmann, and Taudes (2007).
}

values and summation in equation (29) we obtain

$$
\begin{array}{r}
J_{1}\left(x_{1}, y_{1}, p_{1}, r_{1}\right)=E\left[P_{1}\left(x_{1}, y_{1}, p_{1}, r_{1}, \varepsilon_{1}\right)\right. \\
\left.+\gamma V_{2}\left(x_{2}\left(y_{1}, p_{1}, r_{1}\right), r_{2}\left(p_{1}, r_{1}\right), \varepsilon_{1}\right)\right] .
\end{array}
$$

It turns out that the profit of the second time period $V_{2}\left(x_{2}\left(y_{1}, p_{1}, r_{1}\right), r_{2}\left(p_{1}, r_{1}\right), \varepsilon_{1}\right)$ is not necessarily jointly concave for all $x_{2}$. However, the joint concavity of the first time period's profit $P_{1}\left(x_{1}, y_{1}, p_{1}, r_{1}, \varepsilon_{1}\right)$ is strong enough to dominate the non-concavity of the future profit. This results in joint concavity of the profit function $J_{1}\left(x_{1}, y_{1}, p_{1}, r_{1}\right)$, leading to the optimality of the base-stock policy.

For the case of the linear demand model, one can still find steady-state solutions. Assuming the loss neutral case $\beta_{2}=\beta_{3}$, these are given by

$$
\begin{aligned}
& p^{*}=\frac{\left(\beta_{1} c-\beta_{0}\right)(1-\alpha \gamma)+\beta_{2}(1-\gamma) c}{2 \beta_{1}(1-\alpha \gamma)+\beta_{2}(1-\gamma)} . \\
& y^{*}=E\left[D\left(p^{*}, p^{*}, \varepsilon\right)\right]+F^{-1}\left(\frac{b-(1-\gamma) c}{h+b}\right) .
\end{aligned}
$$

Note that the optimal steady-state price $p^{*}$ in equation (33) is the same as in Section 4.1 and equation (34) corresponds to the optimal steady-state base-stock level obtained in Section 3.2 for the optimal steady-state price $p^{*}$ from equation (33). The proof is a combination of the proofs for the steady states of the models (7) and (24) from the above sections. As in the proof of the joint pricing and inventory without reference effect case, we first find the steady-state inventory. Again the infinite sum representation of equation (28) is rearranged as in the sections before to get

$$
\begin{aligned}
& V\left(x_{1}, r_{1}\right) \\
= & c x_{1}+\sum_{t=0}^{\infty} \gamma^{t} \max _{y_{t+1}, p_{t+1}}\left[p_{t+1} E\left[D\left(p_{t+1}, r_{t+1}\right)\right]\right. \\
& -c(1-\gamma) y_{t+1} \\
& \left.+\gamma c D\left(p_{t+1}, r_{t+1}\right)-G\left(y_{t+1}, p_{t+1}, r_{t+1}\right)\right],
\end{aligned}
$$

where

$$
\text { (36) } \begin{aligned}
& G\left(y_{t+1}, p_{t+1}, r_{t+1}\right) \\
& y_{t+1}-E\left[D\left(p_{t+1}, r_{t+1}\right)\right] \\
&=h \int_{-\infty}^{\infty}\left(y_{t+1}-E\left[D\left(p_{t+1}, r_{t+1}\right)\right]-u\right) f(u) d u \\
& \quad+b \int_{y_{t+1}-E\left[D\left(p_{t+1}, r_{t+1}\right]\right.}^{\infty}\left(u-y_{t+1}-E\left[D\left(p_{t+1}, r_{t+1}\right)\right]\right) f(u) d u .
\end{aligned}
$$


Figure 15: Optimal pricing decision (loss neutral)

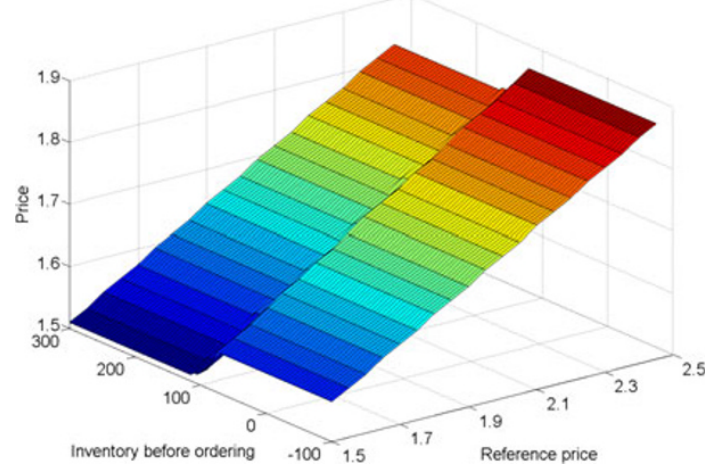

Figure 16: Optimal ordering decision (loss neutral)

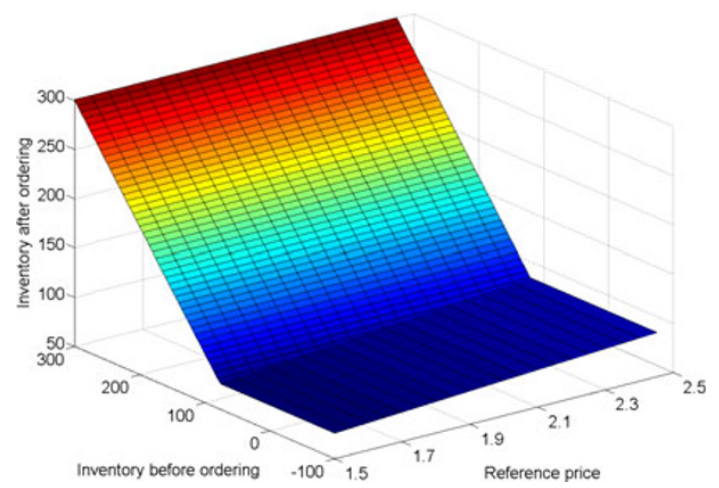

Differentiation with respect to $y$ and using the same arguments as in Section 3.2, we get the steady state base-stock equation (34) depending on the price. Note that the reference price has to be equal to the price as this is necessary for the steady-state price. The steady-state price in formula (33) is found analogously to the proof of the steady state for the reference price model (24) after substituting $y^{*}(p)$ for $y$ in the infinite sum (35) and differentiating with respect to the price $p$. Interestingly, this yields exactly the same steadystate price $p^{*}$ as in Section 4.1.

In the following we present the results for the loss neutral (loss averse) base example with $\beta_{0}=$ $100, \beta_{1}=-20, \beta_{2}=\beta_{3}=-40\left(\beta_{2}=-50, \beta_{3}=\right.$ -30), $c=0.5, \alpha=0.5, \gamma=0.5, b=0.4, h=$ $0.005, T=15$ and a standard deviation $\sigma=20$. Figures 15 to 18 show that a base-stock/list price policy is optimal for all reference prices. From figures 15 and 17 one can see that the optimal price is always increasing in reference price, no matter if we consider loss neutral or loss averse customer behavior. This is true in any time period.
Figure 17: Optimal pricing decision (loss averse)

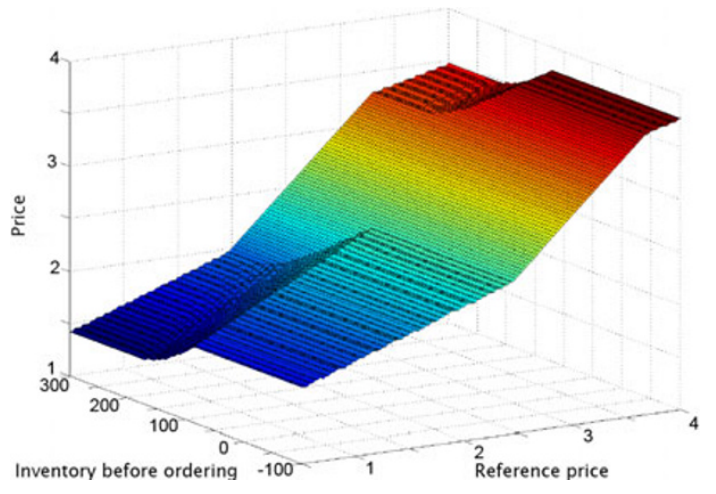

Figure 18: Optimal ordering decision (loss averse)

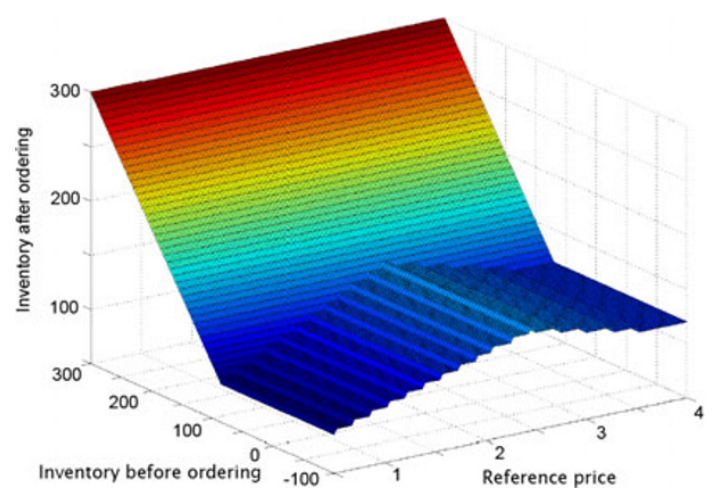

However, the optimal ordering quantity is only increasing in reference price in the loss neutral case (see Figure 16). In contrast Figure 18 shows that the optimal inventory after ordering is not monotonous in reference price in the case of loss aversion. Due to this added complexity we will concentrate on the loss neutral case for the rest of the paper.

Similar to Figure 4, one can see from Figure 19 that price discounts for high inventory levels before ordering are also given in the reference price case. However, due to the negative carry-over effects, these are generally smaller than in the classical setting. Also note the generally lower price level in the model including reference price effects.

In the model of Section 3.2 price discounts are given at a higher inventory level, the more time is left in the planning horizon (see Figure 4). In the model from this section price discounts are generally smaller and are given as soon as the inventory level before ordering is higher than the base-stock level (see Figure 19). Since we give smaller discounts, we have to react earlier in time in order to 
Figure 19: Price trajectories in inventory level $x_{0}$

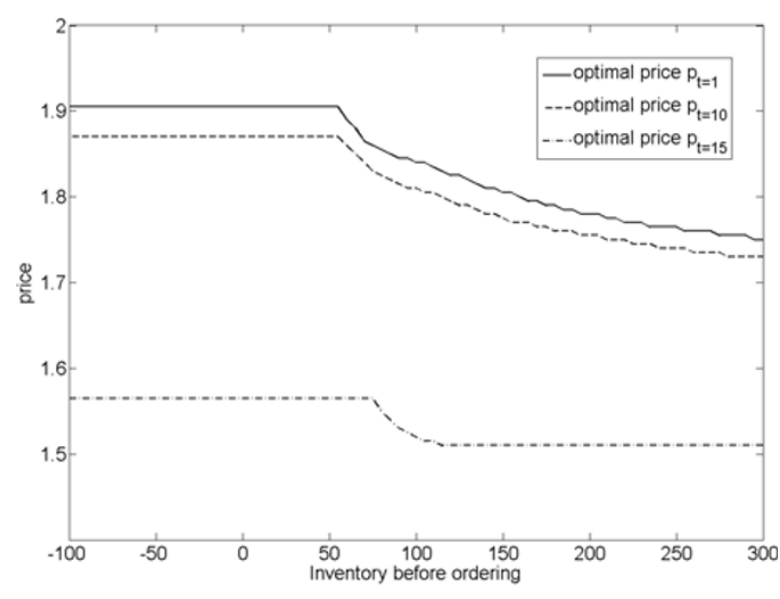

Figure 20: List-price trajectories in reference price

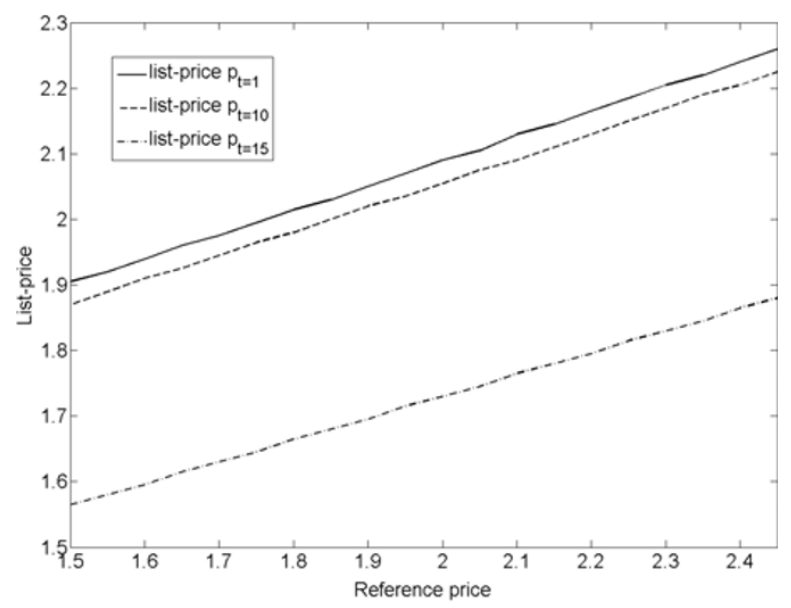

move the inventory level before ordering below the steady-state level and thus reach a possible steady state.

The model in Section 3.2 aims at reducing basestocks over time and thus list prices are increasing over time (see Federgruen and Heching (1999)). If variance is independent of price, list prices tend to be constant over time (see Figure 5). In contrast the model in this section behaves qualitatively completely different. Here, similar to Figure 11, list prices are decreasing over time in order to benefit from the reference price effects (see Figure 20). With decreasing prices and also the resulting reference price effect, expected demands are increasing necessitating higher base-stock levels (see Figure 21).

As in sections 2.2 and 4.1 one can study the behavior of the steady-state solutions for our com-
Figure 21: Base-stock trajectories in reference price

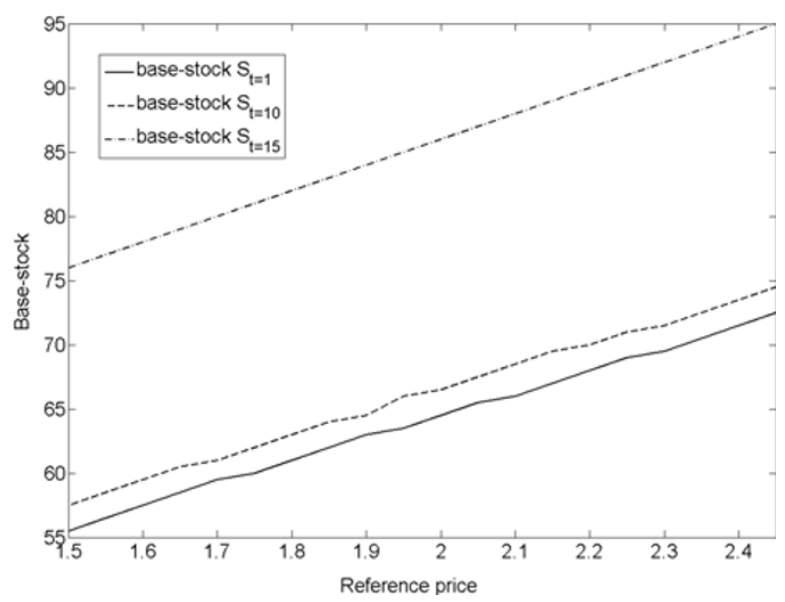

bined model. Using the steady-state formulas (33) and (34) we can describe the behavior of the steady states in the memory parameter $\alpha$, the discount factor $\gamma$ and the reference effect $\left|\beta_{2}\right|$. Note here that $\beta_{2} \leq 0$. For examples of the behavior with respect to these parameters see table 3. Differentiating $p^{*}$ with respect to $\alpha$ and $\beta_{2}$, we get $\frac{\partial p^{*}}{\partial \alpha}=\frac{\gamma \beta_{2}(1-\gamma)\left(\beta_{0}+\beta_{1} c\right)}{\left(2 \beta_{1}(1-\alpha \gamma)+\beta_{2}(1-\gamma)\right)^{2}}<0$ and $\frac{\partial p^{*}}{\partial \beta_{2}}=$ $\frac{(1-\gamma)(1-\alpha \gamma)\left(\beta_{0}+\beta_{1} c\right)}{\left(2 \beta_{1}(1-\alpha \gamma)+\beta_{2}(1-\gamma)\right)^{2}}>0$. Since we do not allow for prices below ordering costs, the inequalities hold as thus $\beta_{0}+\beta_{1} c>\beta_{0}+\beta_{1} p>0$ for all $p$. Hence, $p^{*}$ is decreasing in $\alpha$ and $\left|\beta_{2}\right|$. As $F^{-1}\left(\frac{b-(1-\gamma) c}{h+b}\right)$ is independent of both $\alpha$ and $\beta_{2}$ and demand is decreasing in price, $E\left[D\left(p^{*}, \varepsilon\right)\right]$ is increasing in $\alpha$ and $\left|\beta_{2}\right|$. As a consequence, $y^{*}$ is increasing in $\alpha$ and $\left|\beta_{2}\right|$. Furthermore, $\frac{\partial p^{*}}{\partial \gamma}=\frac{-\beta_{2}(1-\alpha)\left(\beta_{0}+\beta_{1} c\right)}{\left(2 \beta_{1}(1-\alpha \gamma)+\beta_{2}(1-\gamma)\right)^{2}}>0$ and hence, $p^{*}$ is increasing in the discount factor. However, for $\gamma$ one cannot make a definite statement about the base-stock, as the safety stock is increasing in $\gamma$ while $E\left[D\left(p^{*}, \varepsilon\right)\right]$ is decreasing in $\gamma$. As a result, in cases of small uncertainty in demand

\section{Table 3: Steady-state base-stock and optimal price}

\begin{tabular}{lcccc}
$\alpha$ & 0 & 0.33 & 0.66 & 1 \\
\hline$p_{\alpha}^{*}$ & 2.70 & 2.67 & 2.61 & 2.00 \\
\hline$S_{\alpha}^{*}$ & 47 & 49 & 51 & 53 \\
\hline$\beta_{2}$ & 0 & -20 & -40 & -60 \\
\hline$p_{\beta_{2}}^{*}$ & 2.75 & 2.65 & 2.55 & 2.47 \\
\hline$S_{\beta_{2}}^{*}$ & 38 & 40 & 44 & 46 \\
\hline$\gamma$ & 0.75 & 0.85 & 0.95 & 1 \\
\hline$p_{\gamma}^{*}$ & 2.38 & 2.49 & 2.65 & 2.75 \\
\hline$S_{\gamma}^{*}$ & 62 & 67 & 76 & 90 \\
\hline
\end{tabular}


Figure 22: Sequential optimization versus joint optimization

\begin{tabular}{|c|c|}
\hline Sequential Optimization: & Joint Optimization: \\
\hline $\begin{array}{l}\text { Marketing: } \\
\qquad \begin{aligned} \max _{p} & \sum_{t=0}^{T} \gamma^{t}\left[\left(p_{t+1}-c\right) E\left[D\left(p_{t+1}, r_{t+1}\right)\right]\right] \\
& \Rightarrow p^{*}(r)=\left[p_{\mathbf{1}}^{*}\left(r_{1}\right), \ldots, p_{T}^{*}\left(r_{T}\right)\right] \\
& \Rightarrow r^{*}=\left[r_{\hat{1}}^{*}, \ldots, r_{T}^{*}\right]\end{aligned}\end{array}$ & $\begin{array}{c}\max _{y, p} \sum_{t=0}^{T} \gamma^{t}\left[\left(p_{t+1}\right) E\left[D\left(p_{t+1}, r_{t+1}\right)\right]+\right. \\
\left.+c\left(y_{t+1}-x_{t+1}\right)\right)- \\
\left.-G\left(y_{t+1}, p_{t+1}, r_{t+1}\right)\right]\end{array}$ \\
\hline $\begin{array}{l}\text { Production: } \\
\begin{aligned} & \max _{y} \sum_{t=0}^{T} \gamma^{t}\left[\left(p_{t+1}^{*}\right) E\left[D\left(p_{t+1}^{*}, r_{t+1}^{*}\right)\right]+\right. \\
& \\
&\left.\quad+c\left(y_{t+1}-x_{t+1}\right)\right)- \\
&\left.-G\left(y_{t+1}, p_{t+1}^{*}\right)\right] \\
& \Rightarrow y^{*}(x)=\left[y_{1}^{*}\left(x_{1}\right), \ldots, y_{T}^{*}\left(x_{T}\right)\right]\end{aligned}\end{array}$ & $\begin{array}{l}\Rightarrow y^{*}(x, r)=\left[y_{1}^{*}\left(x_{1}, r_{1}\right), \ldots, y_{T}^{*}\left(x_{T}, r_{T}\right)\right] \\
\Rightarrow p^{*}(x, r)=\left[p_{1}^{*}\left(x_{1}, r_{1}\right), \ldots, p_{T}^{*}\left(x_{T}, r_{T}\right)\right]\end{array}$ \\
\hline Optimal total expected profit: $\operatorname{seq} V_{T}^{\wedge}\left(x_{1}, r_{1}\right)$ & Optimal total expected profit: joint $V_{T}^{*}\left(x_{1}, r_{1}\right)$ \\
\hline
\end{tabular}

the base-stock is decreasing in $\gamma$ whereas for large uncertainty the base-stock is increasing in $\gamma$. For the rest of the paper we investigate the differences between a sequential and a joint optimization approach (see Figure 22). In the sequential approach first the marketing/sales department determines an optimal price without considering any inventory decisions and taking demand fulfillment for granted. This price is then passed on to the production unit of the company which then decides on an optimal stocking quantity without having the possibility to change the price. In the joint approach both decisions are taken simultaneously. In figures 23 and 24 we compare the optimal base-stock and price/reference price paths for the

Figure 23: Price path (sequential vs joint optimization)

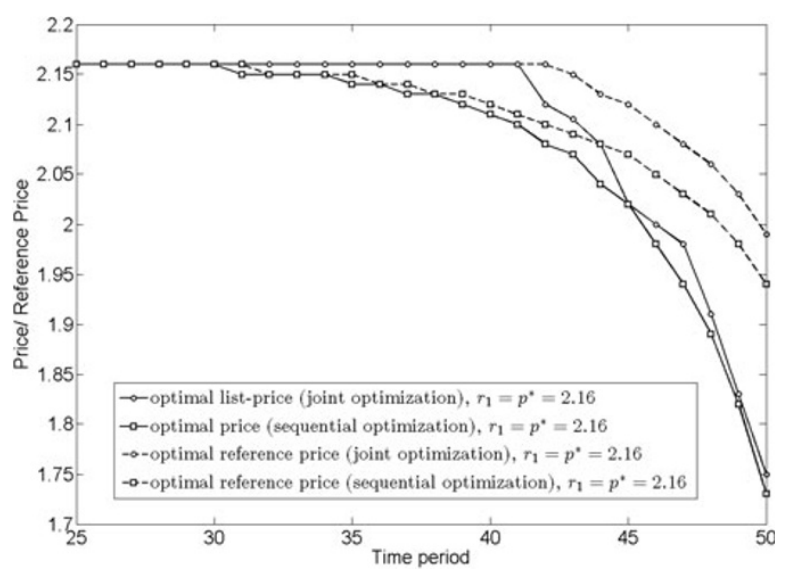

sequential and joint approach from Figure 22. For the time being we assume $r_{1}=p^{*}$ and $x_{1}=0$ to avoid having a transient phase at the beginning of the planning horizon. Using joint optimization, price and base-stock leave the steady state later. This is because we have the opposing strategies of benefitting from the reference effects by lowering prices towards the end of the planning horizon (see Figure 11) and aiming at a clearance of stock at the end of the planning horizon (see Figure 5).

The question now is how such a joint optimization of price and inventory increases the benefits over the sequential optimization. Figure 25 shows that similar to Figure 6 we get the largest benefits of joint optimization towards the end of, or for

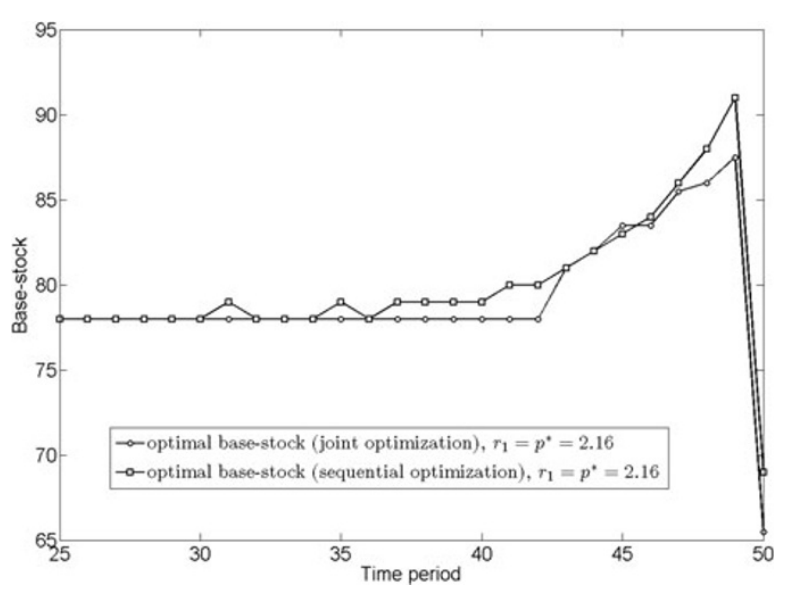


Figure 25: Profit increase over time

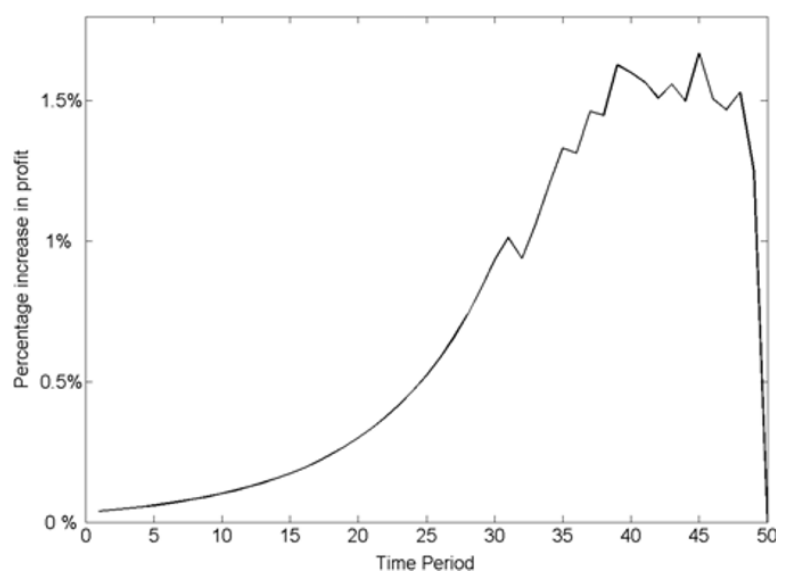

Figure 26: Profit increase in inventory level $x_{0}$

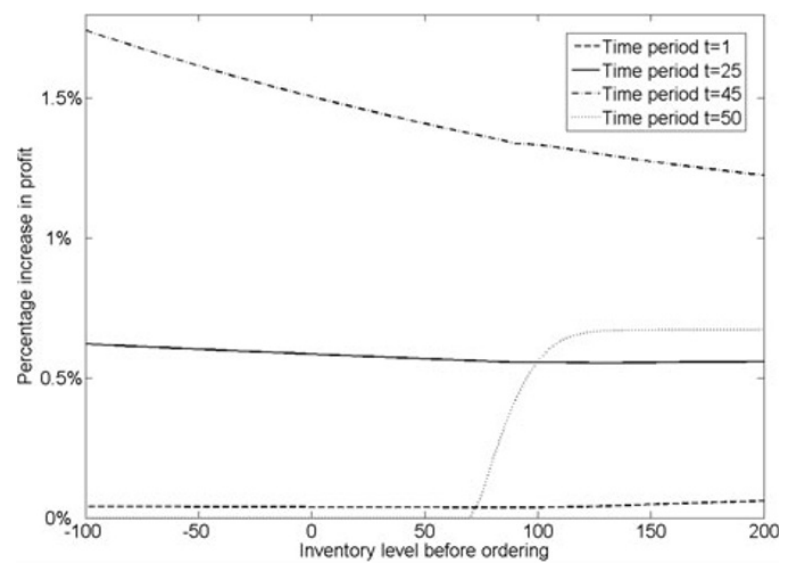

a short planning horizon. In contrast to the comparisons in Federgruen and Heching (1999), who base all numerical results on a coefficient of variation, we always use a constant standard deviation (not depending on price). As in Section 3.2 this results in generally relatively low benefits. Again Figure 25 shows relatively low benefits, which can be much higher for substantially larger inventory levels before ordering (see Figure 26 for the last time period $t=50$ ). Similar to Figure 7 this effect can be observed for any time period $t$. However, in comparison to the model without reference effects, for smaller $t$ this effect only appears for inventory levels before ordering much higher than 200. This is because the pricing strategy under reference price effect enables us to clear higher stock levels in later time periods.
Figure 27: Profit increase in reference effect

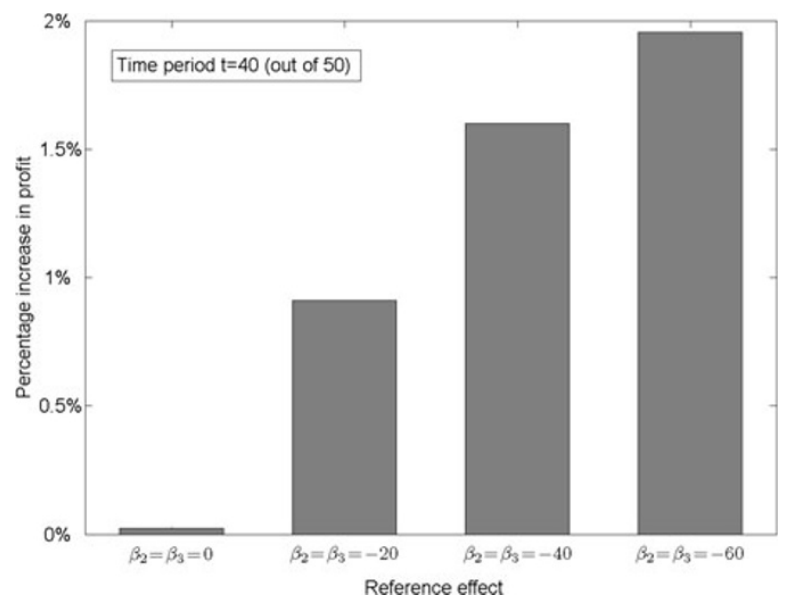

Figure 28: Profit increase in reference price $r_{1}$

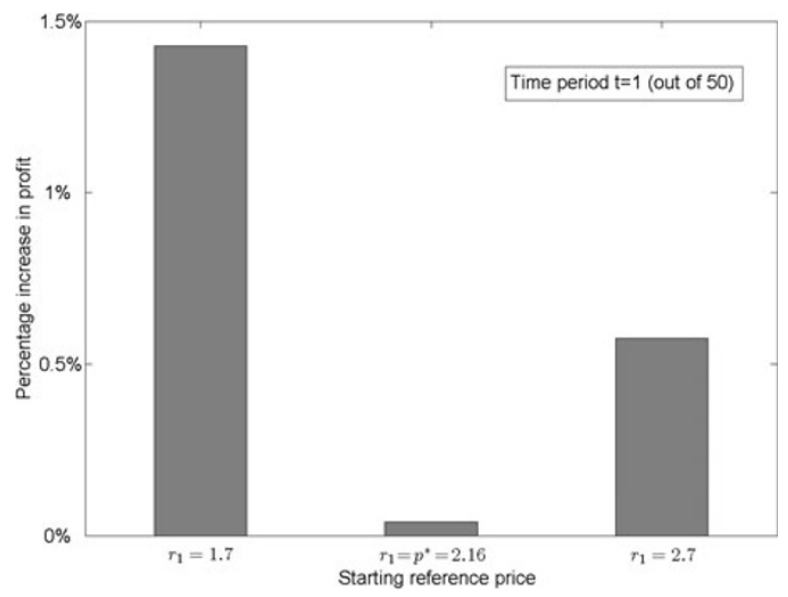

Figure 27 shows that the benefit of the joint model with reference effect is at least 10 times the benefit of the model without reference effect, and is considerably higher than when the reference effect gets larger. While in the classical setting price is only varied to control inventory, here price has its own dynamics, and incorporating the influence of the reference price increases the benefits of integrating pricing and inventory control significantly. Moreover, a significant difference to the model of Section 3.2 is that while there the benefit converges to zero for long planning horizons, here the benefit converges to a value considerably higher than zero (depending on the parameters chosen). This effect is more prominent the more the starting reference price differs from the optimal steady-state price (see Figure 28). 


\section{Conclusion and Directions for Future Research}

In this paper we surveyed the results on the gains of integrating pricing and inventory control for the case when inventory can be set and demand is stochastic. Then we investigated whether using a reference price model to describe demand increases the benefits of integration with a logistic model. Here, we studied whether the base-stock list-price policy still holds in such a setting and inferred the size of potential benefits via numerical simulation. We found that the benefits increase considerably when reference effects are included, i.e. even with a constant standard deviation we achieved at least 10 times the benefit achieved by the the joint model without a reference price. Also, it turns out that the base-stock policy also holds for the reference price model. However, except for the two-period case with linear demand, this result cannot be proved yet, but our conclusions are well founded on extensive numerical simulations. We also added details to existing literature by studying single-period joint pricing/inventory control with backlogging and by extending the steady-state reference price proof from Popescu and Wu (2007) to the case of positive ordering cost. We furthermore give a steady-state price and inventory for the joint inventory and pricing models with and without reference effects.

Clearly, we are only at the beginning of understanding combined reference price/inventory models: a general proof of the base-stock policy for linear demand is needed; also, the dependence of inventory after ordering and price on the state variables needs to be studied. Fast algorithms for solving (30) and (31) need to be developed, same as suitable heuristics. As in practice the parameters of the demand model have to be estimated, combined estimation and control approaches are a fruitful area of future research, too.

\section{References}

Abad, Prakash L. (2001): Optimal price and order size for a reseller under partial backordering, Computers \& Operations Research, 28 (1): 53-65.

Arrow, Kenneth J., Theodore Harris, and Jacob Marschak (1951): Optimal inventory policy, Econometrica, 19 (3): 250272.

Bellman, Richard E., Irving Glicksberg, and Oliver Gross (1955): On the optimal inventory equation, Management Science, 2 (1): 83-104.
Briesch, Richard A., Lakshman Krishnamurthi, Tridib Mazumdar, S. P. Raj (1997): A comparative analysis of reference price models, Journal of Consumer Research, 24 (2): 202-214.

Chen, Xin, David Simchi-Levi (2004)a: Coordinating inventory control and pricing strategies with random demand and fixed ordering cost: The finite horizon case, Operations Research, 52 (6): 887-896.

Chen, Xin, David Simchi-Levi (2004)b: Coordinating inventory control and pricing strategies with random demand and fixed ordering cost: The infinite horizon case, Mathematics of Operations Research, 29 (3): 698-723.

Dye, Chung-Yuan, Tsu-Pang Hsieh, Liang-Yuh Ouyang (2007): Determining optimal selling price and lot size with a varying rate of deterioration and exponential partial backlogging, European Journal of Operational Research, 181 (2): 668-678.

Elmaghraby, Wedad, Pinar Keskinocak (2003): Dynamic pricing in the presence of inventory considerations: Research overview, current practices, and future directions, Management Science, 49 (10): 1287-1309.

Federgruen, Awi, Aliza Heching (1999): Combined pricing and inventory control under uncertainty, Operations Research, 47 (3): 454-475.

Fibich, Gadi, Arieh Gavious, Oded Lowengart (2003): Explicit solutions of optimization models and differential games with nonsmooth (asymmetric) reference-price effects, Operations Research, 51 (5): 721-734.

Gimpl-Heersink, Lisa, Christian Rudloff, Moritz Fleischmann, Alfred Taudes (2007): Integrated pricing and inventory control with reference price effects, URL http://idscm.wu-wien. ac.at/own_pubs/InventoryPriceReferencePriceModel.pdf.

Greenleaf, Eric (1995): The impact of reference price effects on the profitability of price promotions, Marketing Science, 14 (1): 82-104.

Khouja, Moutaz (1996): A note on the newsboy problem with an emergency supply option, The Journal of the Operational Research Society, 47 (12): 1530-1534.

Kopalle, Praveen K., Ambar G. Rao, Joao L. Assuncao (1996): Asymmetric reference price effects and dynamic pricing policies, Marketing Science, 15 (1): 60-85.

Mazumdar, Tridib, S.P. Raj, Indrajit Sinha (2005): Reference price research: Review and propositions, Journal of Marketing, 69 (4): 84-102.

Montgomery, Douglas C., M. S. Bazaraa Ajit, K. Keswani (1973): Inventory models with a mixture of backorders and lost sales, Naval Research Logistics Quarterly, 20 (2): 255-263.

Moon, Sangkil, Gary J. Russell, Sri Devi Duvvuri (2006): Profiling the reference price consumer, Journal of Retailing, 82 (1): 1-11.

Natter, Martin, Thomas Reutterer, Andreas Mild, and Alfred Taudes (2006): An assortment-wide decision-support system for dynamic pricing and promotion planning in DIY retailing. Marketing Science, 26: 576-583.

Petruzzi, Nicholas C., Maqbool Dada (1999): Pricing and the newsvendor problem: A review with extensions, Operations Research, 47 (2): 183-194.

Phillips, Robert L. (2005): Pricing and Revenue Optimization, Stanford University Press.

Popescu, Ioana, and Yaozhong Wu (2007): Dynamic pricing strategies with reference effects, Operations Research, 55 (3): 413-429. 
Slonim, Robert, and Ellen Garbarino (2002): Similarities and differences between stockpiling and reference effects, Working paper, Case Western Reserve University.

Talluri, Kalyan T., and Garrett J. van Ryzin (2004): The Theory and Practice of Revenue Management, Kluwer Academic Publishers.

Thomas, L. Joseph (1974): Price and production decisions with random demand, Operations Research, 22 (3): 513-518.

Whitin, T. M. (1955): Inventory control and price theory, Management Science, 2 (1): 61-68.

Winer, Russel S. (1986): A reference price model of brand choice for frequently purchased products, Journal of Consumer Research, 13 (2): 250-256.

Yano, Candace, and Stephen Gilbert(2004): Coordinated pricing and production procurement decisions: A review, in Amiya Chakravarty and Jehoshua Elishaberg, (eds.), Managing Business Interfaces: Marketing, Engeneering, and Manufacturing Perspectives Series: International Series in Quantitative Marketing, Springer, Heidelberg, 65-103.

Zheng, Yu-Sheng (1991): A simple proof for optimality of $(\mathrm{s}, \mathrm{S})$ policies in infinite-horizon inventory systems, Journal of Applied Probability, 28 (4): 802-810.

\section{Biographies}

Lisa Gimpl-Heersink is Diplom Ingenieur (Master of Science) in Technical Mathematics (Operations Research, Statistics and Management Science) at Graz University of Technology, Austria. Academic working and teaching experience as assistant lecturer and scientific assistant at Graz University of Technology, and the University of Leoben. Non-academic working experience in life-insurance mathematics and logistic software algorithm design. Currently doctoral candidate in 'Economics and Social Sciences' and research associate within the project 'Integrated Demand and Supply Chain Management' at the Vienna University of Economics and Business Administration, Institute of Production Management. Research interests: supply chain management, pricing and inventory control models (numerical and analytical optimization), dynamic programming.
Christian Rudloff is currently project assistant for the WWTF project "Integrated Demand and Supply Chain Management" (WU Wien). MSc. and Ph.D. in Mathematics, University of East Anglia, UK. Studied Mathematics with minor in Management, University Regensburg, Germany. Experience in econometrics as project assistant, FWF project "Identifikation multivariater dynamischer Systeme" (TU Wien). Industry experience (CACI, London, 2002-2003) building geographical databases for marketing management. Teaching experience as a lecturer at Carnegie Mellon University and Chatham College, Pittsburgh, USA (2003-2005). Research Areas: supply chain management, pricing and inventory control models, time series analysis, econometrics.

Moritz Fleischmann is an Associate Professor of Supply Chain Management at Rotterdam School of Management, Erasmus University. He received his $\mathrm{Ph} . \mathrm{D}$. in General Management from Erasmus University in 2000. He was a visiting researcher at the Tuck School of Business and at INSEAD. Moritz is currently teaching in the MBA and MScBA programs of RSM Erasmus University. His research addresses various topics in the field of supply chain management. Current focal points include coordination of revenue management and operations, multi-channel distribution, in particular e-fulfillment, and closed-loop and sustainable supply chains. In these fields, Moritz has been working with companies such as IBM, Heineken, and Albert Heijn.

Alfred Taudes Visiting Professor, University of Tsukuba, Japan (1997/98), Speaker of the Special Research Area "Adaptive Information Systems and Modeling in Economics and Management Science" (2000-2005), Coordinator of the WWTF project "Integrated Demand and Supply Chain Management." Within Call "Mathematics and ..." (2005-2008). Publications, e.g. in Management Science, MIS Quarterly, Marketing Science, Journal of Management Information Systems, Professor for Business Administration and MIS at the Vienna University of Economics and Business Administration, Institute for Production Management. Head of Department for Information Systems and Process Management. Research Areas: supply chain management, marketing science, revenue management. 